\title{
Gerhard Fouquet
}

\section{Zeit, Arbeit und Muße im Wandel spätmittel- alterlicher Kommunikationsformen}

\author{
Die Regulierung von Arbeits- und Geschäftszeiten \\ im städtischen Handwerk und Gewerbe
}

Ulf Dirlmeier zum 60. Geburtstag

\section{Glocken, Uhren und Öffentlichkeit}

Im Jahre 1497 wurde in Erfurt eine Glocke für den „Dom“, für die Stiftskirche St. Marien, gegossen. Zwei Hochöfen waren dafür aufgestellt, die Lehmform bereitet und gebrannt worden. Der Chronist Konrad Stolle erzählt, daß der GlockengieBer am 7. Juli, „als [es] eyns slugk noch mittage“, Feuer in den beiden Öfen anzünden ließ. Die Glockenspeise "wart gar in der nacht, als czeene slugk ${ }^{*}$. Und als es ein Uhr nachts geworden war, wurde das geschmolzene Metall in die Glockenform abgelassen. „Do es czwey slugk, do was das wergk lobelichen unnd follekomen wol" vollbracht ${ }^{1}$.

Uhr und Glocke am Ende des 15. Jahrhunderts: Sie setzten in den europäischen Städten das Zeitmaß, sie rhythmisierten und normierten durch ihre optischen und akustischen Zeichen, durch ihre Signale die urbane Tageschronologie Messe, Andacht und Stundengebete in Kirchen und Klöstern, Verwaltung und Gericht in den Rathäusern, die Sicherheit der Stadt an den Toren, auf den Türmen und in den Gassen, die in Form von Tugendkatalogen in den gehobenen stadtbürgerlichen Haushalten bereits ausgebildete „Zeitökonomie"2 und eben auch den Arbeitstag

${ }^{1}$ Richard Thiele (Bearb.), Konrad Stolle. Memoriale - thüringisch-erfurtische Chronik (Geschichtsquellen der Provinz Sachsen und angrenzender Gebiete 39, Halle 1900) 466, nr. 364. Der Glockenguß fand vor einem Sakramentstisch statt: Rolf Sprandel, Chronisten als Zeitzeugen. Forschungen zur spätmittelalterlichen Geschichtsschreibung in Deutschland (Kollektive Einstellungen und sozialer Wandel im Mittelalter NF 3, Köln, Weimar, Wien 1994) 262.

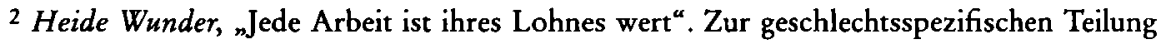
und Bewertung von Arbeit in der Frühen Neuzeit, in: Karin Hausen (Hrsg.), Geschlechterhierarchie und Arbeitsteilung. Zur Geschichte ungleicher Erwerbschancen von Männern und Frauen (Göttingen 1993) 19-39, bes. 22. 
auf den Baustellen und in den Werkstätten, die Handels-, Gewerbe- und Verkehrszeiten auf Marktplätzen, in Läden und Buden, in den Wirtshäusern bis hin zum Anzeigen der Badestunden in den Wildbädern ${ }^{3}$.

Arbeit und Nichtarbeit der Tagelöhner, Arbeits- und Geschäftszeiten der Handwerker und Händler waren zunächst durch die Kirche und ihre kompendiarische Stundenreihe geprägt worden. Seit der zweiten Hälfte des 14. Jahrhunderts sorgten nördlich der Alpen die allenthalben installierten öffentlichen Schlaguhren für Veränderungen, verhältnismäßig früh schon, 1366, in Zürich4. Die Tages-, auch die Nachtzeiten wurden dadurch weniger säkularisiert als vielmehr den sich wandelnden Bedürfnissen der städtischen Bürgerschaft angepaßt - allerdings in Grenzen: Präzisierung, Befristung, Koordination sind Schlagwörter für jene Entwicklung 5 . Stadtglocken und Stadtuhren, aufgehängt in Türmen, angebracht an Rathäusern, waren am Ende des Mittelalters zu Trägern der kommunalen Identität geworden, wurden nicht nur im repräsentativen Sinn, sondern auch in der alltäglichen Praxis selbst zu Zeichen der „urbanitas"6. Was den größeren deutschen Städten schon seit der zweiten Hälfte des 14. Jahrhunderts geläufig war, das holten kleinere Städte wenige Generationen später nach: In Siegen beispielsweise hat die Stadt in den Jahren 1461 und 1462 einen Kirchturm bei St. Nikolai errichten und dort eine Schlaguhr installieren lassen? ${ }^{7}$ Reisende des 16. Jahrhunderts beobachte-

${ }^{3}$ Zu praktizierten Badezeiten in den Bädern beispielsweise: Benedikt Greiff (Bearb.), Tagebuch des Lucas Rem aus den Jahren 1494-1541. Ein Beitrag zur Handelsgeschichte der Stadt Augsburg (Augsburg 1861) 16, 23 f., 26, $28 \mathrm{f}$. Zum Gesamtzusammenhang der Badezeit: $G e-$ org Zappert, Über das Badewesen mittelalterlicher und späterer Zeit, in: Archiv für Kunde österreichischer Geschichts-Quellen 21 (1859) 1-166, bes. $73 \mathrm{f}$., $125 \mathrm{ff}$.

${ }_{4}$ Zu Zürich: Heinrich Zeller-Werdmüller, Hans Nabbolz (Bearb.), Die Zürcher Stadtbücher des XIV. und XV. Jahrhunderts, 3 Bde. (Leipzig 1899-1906) I, 206, nr. 412 (1366: Arbeitsvertrag mit dem Werkmeister Konrad von Kloten zur Installierung der ersten „urgloggen “).

5 Den Aspekt, daß Zeit einem Prozeß der Verweltlichung unterlag, vertritt u.a. Otto Borst, Alltagsleben im Mittelalter (Frankfurt a. M. 1983) 550. Aus der Fülle der Literatur für den allgemeinen historischen Verlauf sei lediglich verwiesen auf: Gustav Bilfinger, Die mittelalterlichen Horen und die modernen Stunden. Ein Beitrag zur Kulturgeschichte (Stuttgart 1892; ND 1969); Karl-S. Kramer, Grundriß einer rechtlichen Volkskunde (Göttingen 1974) 37-46; Rudolf Wendorff, Zeit und Kultur - Geschichte des Zeitbewußtseins in Europa (Opladen 1980).

6 Gerhard Dobrn-van Rossum, Die Geschichte der Stunde. Uhren und moderne Zeitordnungen (München, Wien 1992) 185. Zu den allgemeinen Vorstellungen von Urbanität im Mittelalter: Thomas Zotz, Urbanitas. Zur Bedeutung und Funktion einer antiken Wertvorstellung innerhalb der höfischen Kultur des hohen Mittelalters, in: Josef Fleckenstein (Hrsg.), Curialitas. Studien zu Grundfragen der höfisch-ritterlichen Kultur (Veröffentlichungen des Max-Planck-Instituts für Geschichte 100, Göttingen 1990) 392-451.

${ }^{7}$ Rainer S. Elkar, Gerbard Fouquet, Und sie bauten einen Turm... Bemerkungen zur materiellen Kultur des Alltags in einer kleineren deutschen Stadt des Spätmittelalters, in: Handwerk und Sachkultur im Spätmittelalter (Österreichische Akademie der Wissenschaften, phil.-hist. Kl. SB 513: Veröffentlichungen des Instituts für mittelalterliche Realienkunde Österreichs 11, Wien 1988) 169-201. Die Uhrglocke wurde $1463 \mathrm{im}$ Turm von St. Nikolai aufgehängt: Heinrich von Achenbach, Geschichte der Stadt Siegen, Bd. 1 (Siegen 1894; ND 1978) $173 \mathrm{f}$. 
ten und beachteten die städtischen Uhren und Glocken sowie das von ihnen ausgehende Signalsystem: Für den Fuggerfaktor Hans Dernschwam beispielsweise war um 1550 auf seiner Route nach Konstantinopel das Nicht-mehr-Vorhandensein von "glokhen“ und „sayger" gleichbedeutend mit dem Betreten einer fremden, einer barbarischen Welt ${ }^{8}$.

Ein solches an Uhr und Glocke festzumachendes Bewußtsein der Erfahrung von abstrakteren, zugleich auch immer noch relativen, von Stadt zu Stadt verschiedenen Fristen und ihrer zumindest partiellen Übertragbarkeit bzw. Verallgemeinerungsfähigkeit wurde im deutschsprachigen Raum während zweier Generationen bis etwa 1450 entwickelt ${ }^{9}$. Es setzte und setzt voraus, daß die je verschiedenen akustischen Signale innerhalb der Stadtmauern und ihres unmittelbaren Umlandes auch von allen verstanden worden sind. Die Bedeutung eines Glockenzeichens mußte als sogenannte „Zeigehandlung “ innerhalb der Stadtöffentlichkeit internalisiert, sozial wie rechtlich akzeptiert werden ${ }^{10}$. Kommunikation via akustisches Zeichen und Herstellung von Öffentlichkeit blieben dabei nicht nur auf die Sensation des Ausnahmefalls beschränkt, auf das Läuten der Sturmglocke, auf Trompetenstöße, die im Aachen des 14. Jahrhunderts das Ausrufen der neu festgesetzten Währungsvalvationen ankündigten ${ }^{11}$. Großstädte wie Venedig verfügten über ein die Tageschronologie an Werktagen sehr genau regulierendes Signal-

${ }^{8}$ Franz Babinger (Bearb.), Hans Dernschwam's Tagebuch einer Reise nach Konstantinopel und Kleinasien (1553/55) (Studien zur Fugger-Geschichte 7, München, Leipzig 1923; ND 1986) 29. Zu weiteren Beobachtungen von Reisenden im 16. Jahrhundert sei besonders verwiesen auf: Maurice Rat (ed.), Montaigne. Journal de voyage en Italie par la Suisse et l'Allemagne en 1580 et 1581 (Paris 1955) 15f., 26, 41, 45, 64.

${ }^{9} \mathrm{Zu}$ den "städtischen Monaden“, den unterschiedlichen Uhrzeiten und Signalensembles: Jacques Le Goff, Die Arbeitszeit in der "Krise“ des 14. Jahrhunderts: Von der mittelalterlichen zur modernen Zeit, in: ders., Für ein anderes Mittelalter. Zeit, Arbeit und Kultur im Europa des 5.-15. Jahrhunderts (Frankfurt a.M., Berlin, Wien 1984) 29-42, bes. 36; Dobrnvan Rossum, Stunde, 190-199. Als Einzelbeispiel: Marius Fallet-Scheurer, Die Zeitmessung im alten Basel, in: Basler Zeitschrift für Geschichte und Altertumskunde 15 (1916) 237-366. $10 \mathrm{Zu}$ den "Zeigehandlungen“: Robert Jütte, Funktion und Zeichen. Zur Semiotik herrschaftlicher Kommunikation in der Stadtgesellschaft, in: Anzeiger des Germanischen Nationalmuseums (1993) 13-21, bes. $14 \mathrm{f}$. Zur Definition von Öffentlichkeit im Mittelalter („öffentlich ist, was von jedermann zur Kenntnis genommen werden kann"): Josef Benzinger, Zum Wesen und zu den Formen von Kommunikation und Publizistik im Mittelalter. Eine bibliographische und methodologische Studie, in: Publizistik 15 (1970) 295-318, bes. 307. Darüber hinaus im Zusammenhang von Glocken und Öffentlichkeit: Alfred Haverkamp, „....an die große Glocke hängen“. Über Öffentlichkeit im Mittelalter, in: Jahrbuch des Historischen Kollegs (1995) 71-112, bes. 82-89 mit weiterer Literatur. Zur Reichweite und zu dem rechtlichen Geltungsbereich der Glocke: Jacob Grimm, Deutsche Rechtsaltertümer, Bd. 1 (Leipzig 41922) 108; Adalbert Erler, Art. Glocke, in: HRG I (1971) 1706-1708.

11 Zur Sturmglocke und zum Verhältnis Glocke-Banner: Ernst Schubert, „bauerngeschrey“. Zum Problem der öffentlichen Meinung im spätmittelalterlichen Franken, in: Jahrbuch für fränkische Landesforschung 34/35 (1975) 883-907, bes. 888; Haverkamp, Glocke, $106 \mathrm{f}$. Zu Aachen: Josef Gerhard Laurent, Aachener Stadtrechnungen aus dem XIV. Jahrhundert, nach den Stadtarchiv-Urkunden (Aachen 1866) 180, 4 f., 224, 21. 
system. Die vier Glocken von San Marco zeigten noch dazu mit unterschiedlicher Läutdauer Tagesanfang, Wachabzug, Arbeitsbeginn, Pausen, Arbeitsende und Wachaufzug an ${ }^{12}$.

Unser Überblick über die Regulierung von städtischen Arbeits- und Geschäftszeiten mit Hilfe akustischer Kommunikationsmittel hat sich zu beschränken. Die Perspektive ist - mit einigen Seitenblicken auf Niederdeutschland - gerichtet auf die rheinischen und oberdeutschen Städte, von Köln, Marburg und Frankfurt bis Straßburg und Basel, von Erfurt, Nürnberg, München und Wien bis Bern und Zürich. Von der Quellenlage her, aber auch aufgrund der zeitgenössischen sozialen wie wirtschaftlichen Verhältnisse stehen vornehmlich die größeren Städte im Mittelpunkt. Sie und ihre zünftigen Korporationen haben im bemerkenswerten wie bezeichnenden Unterschied zu den hochentwickelten flandrischen und oberitalienischen Kommunen erst seit dem Anfang des 14. Jahrhunderts damit begonnen, zeitlich-kommunikative Regelungen für Handwerk und Gewerbe zu treffen und verstärkt seit der Mitte des 15 . Jahrhunderts auch schriftlich zu fixieren ${ }^{13}$. Die Verspätung Oberdeutschlands von teilweise mehr als einem Säkulum im Hinblick auf die Formulierung solcher ordnungspolitischen Vorstellungen und zünftiger Wirtschaftsgesinnung ist dabei sicherlich nicht in erster Linie ein Überlieferungsproblem!

Es sei hervorgehoben, daß die tradierten Hinweise zu Arbeits-, Gewerbe- und Geschäftszeiten zeitlich, lokal und gewerbespezifisch äußerst lückenhaft und uneinheitlich sind. Vor allem entstammen sie vornehmlich städtischen Verordnungsbüchern und Zunftsatzungen, haben also in der Regel normativen Charakter mit allen damit zusammenhängenden methodischen Problemen ${ }^{14}$. Sie zeigen aber im-

12 Dobrn-van Rossum, Stunde, 194-196. Für den deutschen Bereich: Karl Bader, Turm- und Glockenbüchlein. Eine Wanderung durch deutsche Wächter- und Glockenstuben (Gießen 1903) $108 \mathrm{f} ., 122 \mathrm{f}$., passim.

13 Vornehmlich mündliche Tradierung und späte Schriftlichkeit hat man beispielsweise im Luzerner Handwerk wie im gesamten schweizerischen Raum nachgewiesen: Anne-Marie Dubler, Handwerk, Gewerbe und Zunft in Stadt und Landschaft Luzern (Luzerner Historische Veröffentlichungen 14, Luzern, Stuttgart 1982) $149 \mathrm{f}$. Zu mittelrheinischen Verhältnissen: Kurt Wesoly, Lehrlinge und Handwerksgesellen am Mittelrhein. Ihre soziale Lage und ihre Organisation vom 14. bis ins 17. Jahrhundert (Studien zur Frankfurter Geschichte 18, Frankfurt a.M. 1985) 15.

$14 \mathrm{Vgl}$. Helmut Bräuer, Innungsordnungen als Quellen für die Erforschung der bürgerlichen Ideologie, in: Internationales Handwerksgeschichtliches Symposium Veszprém 20.-24.11. 1978 (Veszprém 1979) 324-335; Neithard Bulst, Normative Texte als Quelle zur Kommunikationsstruktur zwischen städtischen und territorialen Obrigkeiten im späten Mittelalter und in der frühen Neuzeit, in: Kommunikation und Alltag in Spätmittelalter und früher Neuzeit (Österreichische Akademie der Wissenschaften, phil.-hist. Kl, SB 596: Veröffentlichungen des Instituts für Realienkunde des Mittelalters und der frühen Neuzeit 15, Wien 1992) 127-144. Hinweise darauf auch bei: Harry Kübnel, Normen und Sanktionen, in: ders. (Hrsg.), Alltag im Spätmittelalter (Graz, Wien, Köln ${ }^{3} 1986$ ) 26-38; Peter Michael Lipburger, Bürgerschaft und Stadtherr. Vom Stadtrecht des 14. Jahrhunderts zur Stadt- und Polizeiordnung des Kardinals Matthäus Lang (1524), in: Heinz Dopscb (Hrsg.), Vom Stadtrecht zur Bürgerbeteiligung. Festschrift 700 Jahre Stadtrecht von Salzburg (Salzburg 1987) 40-63, bes. 47. 
merhin Ordnungsvorstellungen und -prinzipien der Zeit, auch wenn sich die Realitäten gelegentlich anders dargeboten haben mochten, wie z.B. im Kölner Fischkaufhaus des 16. Jahrhunderts, wo die Kaufleute und Wirte dem Aufseher Wein „zum besten“ gaben, „dass man ihn die arbeit nach der uren gestattet und irer abwardet "15. Das Untersuchungsfeld selbst ist wohl bestellt durch ältere wie jüngere handwerks- und gewerbegeschichtliche Arbeiten ${ }^{16}$, durch mehrere Zeitwandel und Kommunikationsformen reflektierende Untersuchungen ${ }^{17}$ sowie durch einige jüngere, Geistes-, Technik- und Sozialgeschichte verbindende Studien ${ }^{18}$.

Wir werden unseren vom Beginn des 14. bis zur Mitte des 16. Jahrhunderts bearbeiteten rheinischen und oberdeutschen Beobachtungsraum in zwei Schritten durchmessen: Es geht zunächst darum, akustisch-kommunikative Signale für die Begrenzung und Rhythmisierung der Arbeits- und Pausenzeiten bei den zahlreichen städtischen Tagelöhnern zu analysieren. Ein zweites Untersuchungsfeld eröffnet sich sodann durch die bei der Begrenzung von Arbeits- und Geschäftszeiten im städtischen Handwerk und Gewerbe beachteten Glockenzeichen, die aus unterschiedlichen Motiven dem Gewerbefleiß Schranken setzten.

Nur hingewiesen sei in diesem Zusammenhang auf ein verwandtes, aber etwas anders geartetes Feld städtischer Ordnungspolitik: Akustische, auch optische Signale begrenzten Markt- und Geschäftszeiten im Groß- und Kleinhandel, machten den Raum des Marktes und die Buden der Krämer zu öffentlichen Foren, zu Orten, die nach Maßgabe der städtischen Ratskollegien und unter Beachtung dirigistischer Prinzipien streng kontrolliert worden sind ${ }^{19}$. Dieser dem „bonum com-

${ }^{15}$ Konstantin Höblbaum, Friedrich Lau, Josef Stein (Bearb.), Das Buch Weinsberg. Kölner Denkwürdigkeiten aus dem 16. Jahrhundert, 5 Bde. (Publikationen der Gesellschaft für Rheinische Geschichtskunde 3, 4 u. 16, Leipzig, Bonn 1886-1926) V, 350.

$16 \mathrm{Vgl}$. vor allem die Arbeiten über die Bedingungen von Tagelöhnern und zur städtischen Lebensmittelversorgung in den folgenden bibliographischen Nachweisen.

${ }^{17}$ Le Goff, Arbeitszeit; Jacques Le Goff, Zeit der Kirche und Zeit des Händlers im Mittelalter, in: Claudia Honegger (Hrsg.), M. Bloch, F. Braudel, L. Febvre u. a.: Schrift und Materie der Geschichte. Vorschläge zur systematischen Aneignung historischer Prozesse (Frankfurt a. M. 1977) 393-414; Klaus Scbreiner, „Diversitas Temporum“. Zeiterfahrung und Epochengliederung im späten Mittelalter, in: Reinhart Herzog, Reinhart Koselleck (Hrsg.), Epochenschwelle und Epochenbewußtsein (Poetik und Hermeneutik 12, München 1987) 361-428, bes. 394-401; Arno Borst, Computus, Zeit und Zahl in der Geschichte Europas (Berlin 1990). 18 Dobrn-van Rossum, Stunde; Stefan Wulf, Arbeit und Nichtarbeit in norddeutschen Städten des 14. bis 16. Jahrhunderts. Studien zur Geschichte sozialer Zeitordnung (Beiträge zur deutschen und europäischen Geschichte 7, Hamburg 1991) mit den bibliographischen Nachweisen der einschlägigen Literatur; Edith Ennen, Zeitbewußtsein in der mittelalterlichen Stadt, in: Peter Dilg, Gundolf Keil, Dietz-Rüdiger Moser (Hrsg.), Rhythmus und Saisonalität. Kongreßakten des 5. Symposions des Mediävistenverbandes in Göttingen 1993 (Sigmaringen 1995) 93-100.

${ }^{19}$ Spätmittelalterliche Mittel- wie Großstädte haben dabei insbesondere den gesamten Bereich des Lebensmittelmarktes stark kontrolliert, die Krämer und Krämerinnen, die Höker, Grempler, Mertzler und Pfragner, und wie sie alle hießen, einem sehr eingeengten Zeitreglement unterworfen, vor allem um den Fürkauf zu unterbinden, aber auch um beispielsweise für die Frische und hygienische Qualität der Waren zu sorgen. Die Nachweise in den städtischen Verordnungsbüchern sind dabei Legion. Verwiesen sei paradigmatisch auf folgende Li- 
mune" unterliegende Bereich städtischer Handels- und Versorgungspolitik kann in der vorliegenden Studie nicht berücksichtigt werden.

\section{Arbeitszeiten und Verdienst: die Tagelöhner}

Thomas Morus hat im zweiten Buch seiner „Utopia“ davon berichtet, daß die Utopier Nacht und Tag in 24 gleich lange Stunden einteilten. Nur sechs davon seien der Arbeit vorbehalten: drei Stunden am Vormittag, drei am Nachmittag nach einer zweistündigen Mittagsruhe. Der Rest des Tages diente der Muße, der Rekreation, der geistigen Weiterbildung. Diese geringen Beschäftigungszeiten reichten, so Morus, zur Erzeugung aller Dinge aus, „die lebensnotwendig sind“, weil alle Bewohner bis auf geringe Ausnahmen zur Arbeit gezwungen seien ${ }^{20}$.

Wahrhaft utopistische Vorstellungen, eine verkehrte Welt! Die gesellschaftlichen Bedingtheiten zu Anfang des 16. Jahrhunderts, die Morus in der Spiegeloptik seiner Utopie verzerrt gebrochen hat, sahen völlig anders aus: Weder war die moderne Stundenrechnung als Voraussetzung für die Neuorganisation von Arbeit überall selbstverständlich noch der Arbeitstag selbst eng begrenzt, Bemessungen allerdings gab es gleichwohl.

Vom Ende einer Entwicklung zurück zu den Urgründen: Am Anfang gehörten allein Gott und der Herrschaft Zeit und Arbeit. Im Florenz des 11. und 12. Jahrhunderts schlugen die Glocken Terz und None und signalisierten damit als Anfang und Ende der Tagesarbeit den Lichttag21. In Basel begann der stadtbürgerliche Lichttag vor der Einführung der Stundenrechnung während der zweiten Hälfte des 14. Jahrhunderts mit der sich immer mehr in den Morgen hinein verschiebenden Matutin bzw. lag in den Sommermonaten bei Sonnenaufgang - die "Tagglocke“ läutete -, das Ende bezeichnete nach Sonnenuntergang das soge-

teratur: Erich Köbler, Einzelhandel im Mittelalter. Beiträge zur betriebs- und sozialwirtschaftlichen Struktur der mittelalterlichen Krämerei (VSWG Bh. 36, Stuttgart 1938) 107-109; Heinz Kimmig/Peter Rüster, Das Konstanzer Kaufhaus. Ein Beitrag zu seiner mittelalterlichen Rechtsgeschichte (Konstanzer Geschichts- und Rechtsquellen 6, Lindau-Konstanz 1954) 56, nr. 17; 61, nr. 21; Anton Herzog, Die Lebensmittelpolitik der Stadt Straßburg im Mittelalter (Abhandlungen zur Mittleren und Neueren Geschichte 12, Berlin, Leipzig 1909) 12, 33 f., 37, 111; Armin Wolf (Bearb.), Die Gesetze der Stadt Frankfurt a. M. im Mittelalter (Veröffentlichungen der Frankfurter Historischen Kommission 13, Frankfurt a. M. 1969) 89, 197, 307. Für Markthoheiten und Markt- bzw. Messezeiten mit ihren akustisch-optischen Übermittlungssystemen z. B.: Wieland Held, Zwischen Marktplatz und Anger. Stadt-LandBeziehungen im 16. Jahrhundert in Thüringen (Weimar 1988) 102-107; Alexander Dietz, Frankfurter Handelsgeschichte, Bd. 1 (Frankfurt a. M. 1910; ND 1970) 37f., 41, 49, 51; Elsbeth Lippert, Glockenläuten als Rechtsbrauch (Das Rechtswahrzeichen 3, Freiburg/Br. 1939) $58-61$.

${ }^{20}$ Edward S. Surtz, J.H. Hexter (Edd.), The Complete Works of St. Thomas More, Bd. 4 (New Haven, London 1965) 126, 128. Deutsche Ubersetzung: Klaus J. Heinisch (Bearb.), Der utopische Staat (Philosophie des Humanismus und der Renaissance 3, Reinbek bei Hamburg 1960; ND 1991) $55 \mathrm{f}$.

${ }^{21}$ Le Goff, Arbeitszeit, 29. 
nannte Neune-Glöcklein 22. Die Luzerner bemaßen ungefähr in der gleichen Zeit den hellen, den „schoenen“ Tag, wie es in Köln heißt, „von fruo, das man ze dien

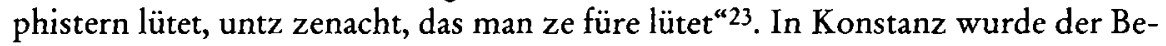
griff des Lichttages noch zu Beginn des 16. Jahrhunderts „vom wachter abblasen bis zum wachter uffblasen“ umschrieben - „die uhre blasen“, nannten dies die Leute von Limburg an der Lahn²4. Im kleinen fränkischen Volkach, wo man noch um 1500 Tag und Nacht die Stunden mit einem Horn meldete, sollte der Türmer, "des morgens eher wan er bläst“, den Tag „anschreien also lautende: Wohlauf, wohlauf, der hochgelobt Tag ist auch auf; Wohlauf, wohlauf, die Faulen und Trägen, die gern länger lägen“ 25 .

Grundsätzlich galt im mittelalterlichen Europa als Einheit für die Arbeit der lichte Tag, bemessen nach dem jahreszeitlichen Wechsel von Sonnenaufgang und -untergang. Daran hat sich auch in den städtischen Lebenswelten seit dem 12. Jahrhundert zunächst wenig geändert. Eine Ordnung für die Nürnberger Bauleute aus der ersten Hälfte des 14. Jahrhunderts faßte diese traditionelle Vorstellung in das zur Verfügung stehende kirchliche Horengeläut: Ein jeder Meister und Tagelöhner soll zu „seinem werke gen, so man fruemesse leutet ze der capelle, und davon gen, so man cumplet leutet" zu St. Egidien ${ }^{26}$. Selbst nach der Einführung der Stundenrechnung richteten sich 1413 bzw. 1422 in der Basler Lohnordnung für das Maurer- und Zimmerergewerbe oder um 1440 in der Berner Rebleuteordnung die täglichen Arbeitsstunden nach dem natürlichen Rhythmus von Sonnenaufgang und -untergang. Dabei hat man die kirchlichen Stunden zumindest beim hereinbrechenden Tag durch Erfahrungswerte über genügendes Arbeitslicht ersetzt: Morgens sollten die Basler Handwerker „früg zư rechter zyt, so sy von dem tag gesehen mógent“, mit ihrem Tagwerk beginnen, „ze nacht, so man complet

22 Fallet-Scheurer, Zeitmessung, 244, 264.

23 Peter Xaver Weber (Bearb.), Luzern ältestes Ratsbüchlein (c. 1300-1402), in: Der Geschichtsfreund. Mitteilungen des historischen Vereins der V Orte 65 (1910) 1-55, bes. 21, nr. 115. Zur Begrifflichkeit in Köln: Heinrich von Loesch (Bearb.), Die Kölner Zunfturkunden nebst anderen Kölner Gewerbeurkunden bis zum Jahre 1500, 2 Bde. (Publikationen der Gesellschaft für Rheinische Geschichtskunde 22, Bonn 1907; ND 1984) I, 99, nr. 32.

${ }^{24}$ Feger, Statutensammlung, 91, nr. 96 (vgl. Anm. Nr. 134); Klaus Eiler (Bearb.), Das Limburger Stadtbuch von 1548. Georg Rauschers "Ordenung der Oberkeit" und andere ausgewählte Quellen zu Bürgerrecht und Stadtverfassung von Limburg im 16. und 17. Jahrhundert (Veröffentlichungen der Historischen Kommission für Nassau 46, Wiesbaden 1991) 116, nr. 67.

${ }^{25}$ Karl-S. Kramer, Fränkisches Alltagsleben um 1500. Eid, Markt und Zoll im Volkacher Salbuch (Würzburg 1985) $32 \mathrm{f}$.

26 Aus dem Nürnberger Satzungsbuch III von 1320/23-ca. 1360: Werner Schultbeiß (Bearb.), Satzungsbücher und Satzungen der Reichsstadt Nürnberg aus dem 14. Jahrhundert, Lfg. 1-2 (Quellen zur Geschichte und Kultur der Stadt Nürnberg 3, Nürnberg 1965-1978) I, $171 \mathrm{f}$. (Das Horengeläut orientierte sich an Sonnenaufgang und -untergang, das Reglement kannte überdies eine unbestimmte Anzahl von Pausen). Älterer leicht fehlerhafter Druck bei: Joseph Baader (Bearb.), Nürnberger Polizeiordnungen aus dem XIII. bis XV. Jahrhundert (Bibliothek des Litterarischen Vereins in Stuttgart 63, Stuttgart 1861; ND 1966) 286. Dazu Peter Fleischmann, Das Bauhandwerk in Nürnberg vom 14. bis zum 18. Jahrhundert (Nürnberger Werkstücke zur Stadt- und Landesgeschichte 38, Nürnberg 1985) 134. 
zen clóstern lutet und davor nit", damit aufhören ${ }^{27}$. Viele Jahrzehnte später definierte eine Graubündner Lohnordnung von 1491 den Arbeitstag noch in ähnlicher Weise: „es soll yeder zue fruyer messzyt an die arbeit stan und nit wychen bis die sonn vergolt ist. ${ }^{\text {28 } 8}$ Schon 1375 hatten bei der Begrenzung der Arbeitszeit der Hamburger Schmiede im Herbst ganz ähnliche Erfahrungen Pate gestanden: wenn ,de sunne to golde geyt ${ }^{\text {“29. }}$.

Die verhältnismäßig großen, in der Literatur häufig unterschätzten Gruppierungen der städtischen Tagelöhner hatten innerhalb dieses derart durch die kirchlichen Horenzeiten und die natürlichen Befindlichkeiten normierten Lichttages kaum Möglichkeiten, die Bedingungen für den Verkauf ihrer eigenen Zeit und Arbeitskraft zu verbessern. Der jahreszeitlich bedingte Wechsel der Tageslänge brachte zwar im Winterhalbjahr kürzere Arbeitszeiten, dafür aber auch einen im Vergleich zu den Sommermonaten geringeren Tagelohn und ein zumindest in kleinen und mittleren Städten in aller Regel wesentlich schlechteres Arbeitsangebot $^{30}$.

Mit der Einführung städtischer Schlaguhren seit der Mitte des 14. Jahrhunderts sollte sich einiges ändern ${ }^{31}$. Gewiß - die Grundordnung des Lichttages als zünftigen Arbeitstag blieb in den Regionen Oberdeutschlands bis zur Industrialisierung im 19. Jahrhundert nahezu unangetastet bestehen, und dies vor allem in den Branchen wie Bau und städtische Landwirtschaft, in denen die Arbeiter im Freien unter den Gesetzen der natürlichen Lichtbedingungen ihr Tagewerk verrichteten. Hier galt nach wie vor Arbeit für Tagelohn als grundsätzlich „unbemessen “32. Die neuen öffentlichen Schlaguhren und das mit ihnen in die Städte einziehende rationalere, weil bemessenere Normensystem ermöglichten es nun aber den Tagelöh-

$27 \mathrm{Zu}$ Basel: Staatsarchiv Basel, Ratsbücher A 5, 71r; Ratsbücher J 1, Rufbuch, I, 37v; FalletScheurer, Zeitmessung, 362; Paul Kölner, Geschichte der Spinnwetternzunft zu Basel und ihrer Handwerke (Basel 1931; ND 1970) 257, nr. 5. Die gleiche Umschreibung konturierte auch die winterlichen Arbeitszeiten. Zu Bern: Friedrich Emil Welti (Bearb.), Die Rechtsquellen des Kantons Bern, T1. I: Stadtrechte, Bd. 2: Das Stadtrecht von Bern (Sammlung Schweizerischer Rechtsquellen, II, 2, Aarau 1939) 79, nr. 118 (Die Tagelöhner in den Berner Weingärten sollten am Werk sein, „so sunn vffgat, vnd nit darab, e denn sunn vergat“).

${ }^{28}$ Fallet-Scheurer, Zeitmessung, 361.

29 Otto Rüdiger (Bearb.), Die ältesten Hamburgischen Zunftrollen und Brüderschaftsstatuten (Hamburg 1874; ND 1976) 252, nr. 48a.

30 Vgl. Gerbard Fouquet, "Item der stette buw “. Finanzen, Organisation und Arbeit in kommunalen Baubetrieben des Spätmittelalters: Eine vergleichende Studie vornehmlich zwischen den Städten Basel und Marburg während des 15. und 16. Jahrhunderts (Habilitationsschrift, Siegen 1994, Maschr.) 53-69, 202-315 (mit Quellen und weiterführender Literatur).

${ }_{31}$ Dazu Carlo M. Cipolla, Clocks and Culture 1300-1700 (London 1967); Klaus Maurice, Die deutsche Räderuhr. Zur Kunst und Technik des mechanischen Zeitmessers im deutschen Sprachraum, 2 Bde. (München 1976) bes. I; Gerhard Dobrn-van Rossum, Rolf Westheider, Die Einführung der öffentlichen Uhren und der Übergang zur modernen Stundenrechnung in den spätmittelalterlichen Städten Niedersachsens, in: Cord Meckseper (Hrsg.), Stadt im Wandel. Kunst und Kultur des Bürgertums in Norddeutschland 1150-1650, Bd. 4 (Stuttgart, Bad Cannstatt 1985) 317-336; Dobrn-van Rossum, Stunde, 124-163.

32 Johann Heinrich Zedler, Großes vollständiges Universallexicon aller Wissenschaften und Künste, Bd. 41 (Leipzig, Halle 1744; ND 1962) $1479 f$. 
nern, den Arbeitstag zur Disposition zu stellen und ihn zu einer freilich „in engen Grenzen vergleichsweise elastische(n) Größe“ zu machen ${ }^{33}$.

Man sollte dabei nicht für jede Veränderung von einiger Tragweite wie für die einsetzende Rationalisierung der täglichen Arbeitszeit die durch die Pest von $1347 / 51$ ausgelöste sogenannte Krise des Spätmittelalters verantwortlich machen ${ }^{34}$. Denn dem durch die Pestumzüge angeblich hervorgerufenen Arbeitskräftemangel stand gewiß kein Wirtschaftsboom mit entsprechenden positiven Sogwirkungen entgegen, und die als Maßstab genommenen Maximallohnfestsetzungen ziehen sich zusammen mit den Klagen über die Tagwerker, welche "die leuth mitt dem taglohn ubersetzen", gleich einem roten Faden schon seit dem 13. Jahrhundert durch die Quellen ${ }^{35}$. Die wenigen zu quantifizierenden Daten belegen eher bei geringen konjunkturell bedingten Abweichungen eine säkulare Stagnationsphase der spätmittelalterlichen Wirtschaft Mitteleuropas von den 1330er bis zu den 1470 er Jahren. Erst danach trat unter dem Eindruck eines wieder langsam Fahrt gewinnenden Bergbaus und einer dadurch entstehenden und mit neuen Technologien arbeitenden Metallindustrie eine nachhaltige Verbesserung der zirkulierenden Geldmenge wie der gesamtwirtschaftlichen Situation gerade in den städtischen Zentren ein ${ }^{36}$.

Nein - nicht Krise und Baisse der Wirtschaft, sondern vornehmlich die neue Zeit der Schlaguhren und ihr akustisches Zeichensystem veränderte langsam und

\section{Dohrn-van Rossum, Stunde, 268.}

34 Vgl. dazu Wilhelm Abel, Agrarkrisen und Agrarkonjunktur. Eine Geschichte der Landund Ernährungswirtschaft Mitteleuropas seit dem hohen Mittelalter (Hamburg ${ }^{31978)} 44$ 103; ders., Strukturen und Krisen der spätmittelalterlichen Wirtschaft (Quellen und Forschungen zur Agrargeschichte 32, Stuttgart, New York 1980); Guy Bois, Crise du féodalisme. Économie rurale et démographie en Normandie orientale du début du $14^{\mathrm{e}}$ siècle au milieu du $16^{\mathrm{e}}$ siècle (Paris 21981). Kritisch dazu z. B. Peter Kriedte, Spätmittelalterliche Agrarkrise oder Krise des Feudalismus, in: Geschichte und Gesellschaft 7 (1981) 42-68; Ernst Schubert, Einführung in die Grundprobleme der deutschen Geschichte im Spätmittelalter (Darmstadt 1992) 5-9 mit weiterer Literatur.

35 Zitat: Stadtarchiv Speyer 1 A 10,f. 15r (1589). Dazu zum Beispiel Wesoly, Lehrlinge, 180194; Dobrn-van Rossum, Stunde, 271-273. Es soll freilich nicht bestritten werden, daß es im unmittelbaren Gefolge der Pest von 1347/51 Arbeitszeit-, vornehmlich aber Lohnkonflikte gegeben hat. Zu verweisen wäre etwa auf den Lohnstreik der Speyerer Weberknechte von 1351, die Lübecker Lohntaxe von 1356: Franz Joseph Mone (Bearb.), Zunftorganisation, in: Zeitschrift für die Geschichte des Oberrheins 17 (1865) 30-68, bes. 56f.; Carl Friedrich Webrmann (Bearb.), Die älteren Lübeckischen Zunftrollen (Lübeck 21872) 391. In Châlonssur-Marne wurden 1369 Arbeitszeit- und Lohnforderungen sogar unter ausdrücklichem Verweis auf die Pest erhoben: Ordonnances des roys de France de la troisième race, Bd. 5 (Paris 1736; ND 1967) $193 \mathrm{f}$.

${ }^{36}$ Dazu mit weiterer Literatur: Wolfgang von Stromer, Kredit und Giralgeld. Zu einer monetären Konjunkturtheorie des Spätmittelalters und der Wende zur Neuzeit, in: Vera Barbagli Bagnoli (Hrsg.), La moneta nell'economica europea, secoli XIII-XVIII (Istituto internazionale di storia economica „F. Datini“ Prato, serie II 7, Florenz 1981) 105-125; ders., Die Struktur von Produktion und Verteilung von Bunt- und Edelmetallen an der Wende vom Mittelalter zur Neuzeit und ihre bestimmenden Faktoren, in: Hermann Kellenbenz (Hrsg.), Precious Metals in the Age of Expansion (Beiträge zur Wirtschaftsgeschichte 2, Stuttgart 1981) 13-26. 
stetig die Haltung der Tagelöhner zu ihrer Arbeitszeit, veränderte bei aller Prädisposition der kaufmännisch-städtischen Oberschichten für Bemessung und $\mathrm{Be}-$ rechnung von Zeit, Raum und Waren aber auch die Einstellungen der handelnden städtischen Räte und der in ihnen vertretenen potentiellen Arbeitsbesitzer ${ }^{37}$. Zwar blieb es im ganzen bei der restriktiven Politik des vollen Lichttages als des traditionellen Maßes der täglichen Arbeit. Die Tagelöhner setzten nun aber in zahllosen Auseinandersetzungen Pausenzeiten und nachvollziehbare Festschreibungen für Arbeitsbeginn und -ende durch. Das eröffnete den Ratsregierungen besonders zum Ende des 15. Jahrhunderts hin die Möglichkeit, durch neue Kontrollen und neue Strafen regulierend in Bereiche einzugreifen, die vorher nur eher informell kontrolliert worden waren.

Uhr und Glocken als im Vergleich zum Horengeläut präzisere kommunikative Mittel der Definition von täglicher Arbeitszeit waren seit der berühmten Werkglocke und -uhr von Amiens des Jahres 1335 eine allgemeine Erscheinung in Europa $^{38}$. Sie sind erst 1374 in einer Kölner Ordnung auszumachen, wahrscheinlich eine der frühesten Satzungen im ganzen deutschsprachigen Raum. Der Kölner Rat legte jedenfalls 1374 fest, daß die Werkleute "morgens yn yren wercken [sollen] sijn, as man luydt an der tzeigen prime, die man ludit yn den vier orden" 39 . Uhrzeit und kirchliche Zeit wurden hier noch merkwürdig parallel formuliert, der Uhrzeiger "zeigte" aber in der Tat die Prime an und ihr Geläut in den Klöstern verkündete den Arbeitsbeginn in der Stadt. Die öffentliche Uhr, kaum installiert, bestimmte also schon nachdrücklich die tägliche Arbeitszeit wie übrigens ein Jahr später auch in Hamburg, wo man sogar die Zeiten der öffentlichen Bäder, fein säuberlich getrennt nach Männern und Frauen, mit Hilfe dieses neuen Instruments festgelegt und bezeichnet hat ${ }^{40}$. Die Kölner Tagelöhner hatten übrigens neben der Festsetzung des Arbeitsbeginns auch eine Bemessung ihrer Mittagspause erreicht: Sie sollten dabei „uss syn eynre uren lanck“ ${ }^{41}$.

${ }^{37}$ Für das „geschärfte Zeitbewußtsein der Kaufleute“: Erich Maschke, Das Berufsbewußtsein des mittelalterlichen Kaufmanns (1964), in: ders., Städte und Menschen. Beiträge zur Geschichte der Stadt, der Wirtschaft und Gesellschaft 1959-1977, in: Vierteljahrschrift für Sozial- und Wirtschaftsgeschichte 68 (Wiesbaden 1980) 380-419, bes. 392-398; Franz Irsigler, Der Alltag einer hansischen Kaufmannsfamilie im Spiegel der Veckinchusen Briefe, in: Hansische Geschichtsblätter 103 (1985) 75-99, bes. 86, 89, 93 ff. Der Nürnberger Kaufmann Hans Praun beispielsweise besaß schon 1476 eine private mechanische Uhr: Horst Pobl, Das Rechnungsbuch des Nürnberger Großkaufmanns Hans Praun von 1471 bis 1478, in: Mitteilungen des Vereins für Geschichte der Stadt Nürnberg 55 (1967/68) 77-136, bes. $96 \mathrm{f}$.

38 Dobrn-van Rossum, Stunde, 275-280.

39 Walther Stein (Bearb.), Akten zur Geschichte der Verfassung und Verwaltung der Stadt Köln im 14. und 15. Jahrhundert, 2 Bde. (Publikationen der Gesellschaft für Rheinische Geschichte 10, 1-2, Bonn 1893-1895) II, 41, nr. 46.

40 Badezeiten z. B. am Werktag: morgens „bis zu zwey Uhren des Tages“ die Frauen ohne Männer, von zwei Uhr „bis man zu dem Thumb Vesper läutet“ die Männer, von der Vesperzeit „bis des Abends“ wiederum die Frauen: Rüdiger, Zunftrollen, 5 f., nr. 3. In der Hamburger Schmiedeordnung von 1375 werden gleichfalls Uhrzeiten zur Bemessung der Arbeitszeit angegeben: ebd., $251 \mathrm{f}$., nr. 48a; Wulf, Arbeit, 66.

41 Stein, Akten, II, $41 \mathrm{f}$., nr. 46. 
Die Stunde als Maß. Sie sollte sich allerdings nicht überall mit der Konsequenz durchsetzen, mit der diese Art von Modernisierung beispielsweise in einer Polizeiordnung der Grafen von Mansfeld aus dem Jahre 1512 durchgeführt worden ist. Doch keine Konsequenz ohne Ausnahme. Es heißt zwar in der Mansfelder Satzung, daß die Tagelöhner in der Zeit zwischen dem 1. Mai und 23. August um vier Uhr zur Arbeit gehen, um sieben und elf Uhr vormittags und um drei Uhr nachmittags Pausen halten und um sieben Uhr feiern sollten, die Periode vom 24. August bis 12. Dezember wird aber lapidar umschrieben: „mit dem Tage an, vnd von der arbeit ${ }^{\prime 42}$. Ähnliche Inkonsequenzen, die aber im Grunde nur die saisonale Unterbeschäftigung während des Winters und damit die stärkere Position der Arbeitgeber widerspiegeln, finden sich zuhauf, etwa auch in Konstanz: Die tägliche Beschäftigungszeit der dortigen Bauleute hat man immerhin noch im Jahr 1520 - wie in Basel rund 100 Jahre zuvor - für die Winterzeit vom 16. Oktober bis 22. Februar mit dem natürlichen Lichtwechsel und kollektiven Erfahrungswerten umschrieben: morgens, „so sy ze werkend gsehend“; abends, „so sy ze werken nit mehr gsehent“. Im Frühjahr und Sommer aber bestimmte die städtische Uhr, akustisch übersetzt durch den mächtigen Glockenschlag „der großen glogken im Munster", den Gang der täglichen Mühsal43. Auch sonst hatte sich die zeitorganisatorische Loslösung der täglichen Arbeitszeit vom Lichttag und den kanonischen Stunden nicht durchgesetzt. Die Grenzen zwischen Tradition und Modernität blieben immer sichtbar, so wenn zum Beispiel 1420 in Ulm der Feierabend der Drescher folgendermaßen festgesetzt wurde: „untz das die glogg driu schlüg oder man die Vesper lüte“, sollten sie tätig sein ${ }^{44}$. Es gab auch ganz handfeste Probleme, Uhrzeit, Geläut und Lichttag zu koordinieren. Noch 1550 veranlaßten solche Schwierigkeiten den Leipziger Rat dazu, von St. Thomas, „wan es zu Morgens frue vier schlecht, alß balt mit einer mittelglocken ein viertel stunde leuten “ zu lassen. Die Stadttore aber seien, wie es in Satzungen der Maurerinnung heißt, einfach "so frue" noch nicht geöffnet, "derwegen man etwas langsamer an die Arbeit kombt“45.

Doch auch die Stunde selbst war noch nicht das gleichsam unveränderliche astronomische Maß moderner Erfahrung. Der zünftige Arbeitstag in Nürnberg richtete sich wie übrigens auch in Regensburg und in einigen kleineren Städten im 15. Jahrhundert nach den astronomischen Tageslängen in einer alternierenden

42 Uwe Schirmer, Nahrungsmittelverbrauch und Lebensmittelkosten im ausgehenden Mittelalter. Beobachtungen aus dem kursächsischen Amt Grimma, in: Sächsische Heimatblätter 2 (1994) 148-155, bes. 153.

${ }_{43}$ "Am morgen an das werk gon, wann es viere schlacht, und abents widerumb drab, wann es sechse schlacht": Otto Feger, Peter Rüster (Bearb.), Das Konstanzer Wirtschafts- und Gewerberecht zur Zeit der Reformation (Konstanzer Geschichts- und Rechtsquellen 11, Konstanz 1961) 118, nr. 189.

44 Carl Mollwo (Bearb.), Das rote Buch der Stadt Ulm (Württembergische Geschichtsquellen 8, Stuttgart 1905) $204 \mathrm{f}$. Dazu auch Dohrn-van Rossum, Stunde, $279 \mathrm{f}$.

45 Helmut Bräuer, Gesellen im sächsischen Zunfthandwerk des 15. und 16. Jahrhunderts (Weimar 1989) $42 \mathrm{f}$. 
Folge von ungefähr drei Wochen ${ }^{46}$. An den kürzesten Tagen während des beginnenden Dezembers belief sich die tägliche Arbeitszeit auf acht Stunden, an den längsten Junitagen hatte man 16 Stunden zu arbeiten. Diese sogenannte Große Uhr Nürnbergs, von der die Baumeisterbücher Lutz Steinlingers und Endres Tuchers aus der zweiten Hälfte des 15. Jahrhunderts Zeugnis ablegen, zählte also die Stunden ungefähr von Sonnenaufgang bis zum Sonnenuntergang ${ }^{47}$. Arbeitsbeginn und Arbeitsende wurden durch das sogenannte Garaus-Geläute angezeigt. Es fiel im Regelfall mit dem Lichttag zusammen; an den Tagen freilich mit 14 bis 16 Arbeitsstunden lag der Anfang des Tagwerks eine Stunde vor dem morgendlichen Garaus, an den Tagen mit 11 bis 16 Stunden wurde mit der Arbeit eine halbe bzw. eine Stunde vor dem eigentlichen Feierabendsläuten Schluß gemacht ${ }^{48}$. Das hatte den Vorteil, daß die Stunden zu verschiedenen Jahreszeiten immer in dem nämlichen Verhältnis zum jeweiligen Lichttag standen. Man brauchte keine Uhr mit ihrem in der Regel komplizierten Zwölfer-System zu benutzen, sondern hörte, unabhängig von der Jahreszeit, nach dem Glockenschlag, wieviele Stunden seit Arbeitsaufnahme verstrichen waren und wieviele noch bis zum Tagesschluß verstreichen würden. Die Praxis des nach Glocken geregelten Arbeitstages wog die Nachteile der spätmittelalterlichen exakten Zeitökonomie auf wie z.B. den Gebrauch ständig ungenauer astronomischer Stundenvergleichstafeln ${ }^{49}$. Nach der Nürnberger Stundenordnung für den kürzesten Tag rhythmisierte die Große Uhr Arbeit und Ruhe im Tagesverlauf folgendermaßen: "Wenn es den tag achte... schlecht, so sol man des morgens an der arbeit sein wenn es den garauß schlecht, und zu dem eßen darvon geen wenn es treu schlecht, und wider zu der arbeit geen wenn es viere schlecht, und des nachtz wenn es den garauß schlecht wider darvon geen." 50

In Basel wie übrigens auch in Straßburg ${ }^{51}$ kannte man bis weit ins 18. Jahrhun-

46 Zur Großen Stunde: Zedler, Universal-Lexikon, Bd. 24 (Leipzig 1740; ND 1962) 1615; Bilfinger, Horen, 229-252; Hermann Grotefend, Zeitrechnung des deutschen Mittelalters und der Neuzeit, 2 Bde. (Hannover 1891-1898; ND 1970) I, 185 f.; Dohrn-van Rossum, Stunde, 112. Zu Regensburg: Carl Theodor Gemeiner, Regensburgische Chronik, 4 Bde. (Regensburg 1803-1821; ND 1971) II, 181.

${ }_{47}$ Ernst Mummenhoff (Bearb.), Lutz Steinlingers Baumeisterbuch vom Jahre 1452, in: Mitteilungen des Vereins für Geschichte der Stadt Nürnberg 2 (1880) 15-77, bes. 60; Matthias Lexer, Friedrich von Weech (Bearb.), Endres Tuchers Baumeisterbuch der Stadt Nürnberg (1464-1475) (Bibliothek des Litterarischen Vereins in Stuttgart 64, Stuttgart 1862; ND 1968) $60 \mathrm{f}$.; Fleischmann, Bauhandwerk, 133.

48 Lexer, Weech, Tuchers Baumeisterbuch, 275; Fleischmann, Bauhandwerk, 135.

${ }^{49}$ Abbildungen solcher Läuttabellen und Vergleichstafeln bei: Maurice, Räderuhr, I, $32 \mathrm{f}$.; Fleischmann, Bauhandwerk, 133, 135.

50 Lexer, Weech, Tuchers Baumeisterbuch, 60.

51 Dazu die Werkmeisterordnung für den städtischen Zimmererhof (Anfang 15. Jahrhundert): (...) „und sol domitte zů rechter zit fürderlichen noch der ersten messen an der stette werg gen und getruwelichen zů deme wercke li̊gen unz an die primezit, also men zeren wurt, also wonlich ist, und dieselbe ürten mit andern zimberlüten und knehten nit lenger sitzen den ein halbe stunde unverlich. und zů den rehten inbeszen so mag er mit sinen gesellen widerumb uffston und fürderlich an der stette werck gen und do getruwelichen arbeiten. und donoch zuo vesperzit so mógent sü eine halbe stunde wol zeren und nit fürbasser und do- 
dert hinein für den zünftigen Arbeitstag eine in Grenzen vergleichbare Regelung ${ }^{52}$. Auch hier in Basel richteten sich die Arbeits- und Essenszeiten nicht nach der astronomischen Uhr, die nach Ortszeit um eine Stunde vorging und von Mitternacht bis Mittag lief ${ }^{53}$, sondern nach dem Geläute, wobei man sich im Gang der Jahreszeiten und des Lichttages auch unterschiedliche Stundenlängen zunutze machte: die Arbeitsglocke schlug bei Tagesanbruch bzw. um fünf Uhr (sechs Uhr Ortszeit) vormittags, die sogenannte Mußglocke um 9 Uhr stand für eine halbstündige Pause, die Non- oder Ave-Maria-Glocken läuteten um 11 Uhr zum Zeichen der einstündigen Mittagsruhe, des „ymbiß“, das Abendbrot-Läuten rief je nach Jahreszeit $z$ wischen 2 und 3 Uhr nachmittags zu einer weiteren halbstündigen Pause, schließlich zeigten die Komplet- und Engelsgrußglocken den Arbeitsschluß bei Einbruch der Abenddämmerung $a^{54}$.

Andere Handwerke Basels freilich orientierten sich bereits während des Spätmittelalters an den um 1380 mit der ersten öffentlichen Schlaguhr im Münster eingeführten astronomischen Zeitregelungen bzw. an der Ortszeit ${ }^{55}$. In der Dienstanweisung für den städtischen Schmiedemeister Basels beispielsweise, wahrscheinlich aus dem späten 15 . Jahrhundert - jedenfalls vor $1481^{56}$-, sollte der Schmied mit seinen Knechten um 5 Uhr morgens (d.h. um 4 Uhr astronomischer Zeit) an die Arbeit gehen und „ze nacht spät, wan es acht schlecht, und nit er

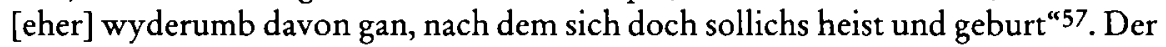
Werkmeister der Schmiede Bastian Krug wußte diese Regelung, die er vor den Abgesandten des Rats 1522/23 vehement verteidigte, auch zu begründen. Schließlich bekäme das Schmiedewerk das ganze Jahr über - sommers wie winters - den gleichen Tagelohn: der Meister täglich 5 Schilling Pfennig, seine Gesellen einen Schilling weniger ${ }^{58}$. Künstliche Unschlittbeleuchtung ermöglichte bei der Arbeitsweise der Schmiede in der Werkstatt die Umformung der alten, von der Natur vorgegebenen Gewohnheiten nach den Gesichtspunkten standardisierter,

noch aber an der stette werck gon und nüt do von wercke lossen denne zwüschen sehssen und sübende, und also man gewönlich an den lon get ungeverlich": Karl Theodor Eheberg (Bearb.), Verfassungs-, Verwaltungs- und Wirtschaftsgeschichte der Stadt Straßburg bis 1681, Bd. 1: Urkunden und Akten (Straßburg 1899) 397, nr. 168.

52 Fallet-Scheurer, Zeitmessung, 360-365.

53 Zur Basler Uhr: Bilfinger, Horen, 253-275; Fallet-Scheurer, Zeitmessung, 297 ff. Die Basler Uhr hat Michel de Montaigne zu den berichtenswerten Kuriosa gezählt: Rat, Montaigne, 15.

54 Zusammenstellung bei: Fallet-Scheurer, Zeitmessung, $364 \mathrm{f}$. Mahlzeiten in Basel (Bauamt): „zů morgen“ eine halbe, „zů ymbiß“ eine und „zů oben" wieder eine halbe Stunde: Staatsarchiv Basel, Bauakten A 2 (Zimmermannseid, Anfang 16. Jahrhundert).

55 Fallet-Scheurer, Zeitmessung, 293.

56 Rudolf Wackernagel, Rudolf Thommen (Bearb.), Urkundenbuch der Stadt Basel, 11 Bde. (Basel 1890-1900), VIII, 480, nr. 615.

57 Staatsarchiv Basel, Bauakten A 2 (Schmiedemeistereid). Im Eid des Werkmeisters der Münsterbauhütte wird von "rechten" bzw. "gesetzten stunden " bei der Begrenzung von Arbeitszeit gesprochen: Emanuel La Roche, Bauhütte und Bauverwaltung des Basler Münsters im Mittelalter, in: Basler Beiträge zur vaterländischen Geschichte 12 (1888) 78-112, bes. 86. 58 Staatsarchiv Basel, Bauakten A 2 (Ratskommission 1522/23). 
überindividueller und rationaler Arbeitszeitgestaltung; das genaue Zeitmaß ersetzte zumindest in diesem Fall das traditionelle "ungevarlich" des Glockengeläuts 59 .

Die Einfallspforte der astronomischen Schlaguhr in den traditionellen akustischen Raum der kanonischen Stunden bzw. der Großen Uhr und ihres Signalensembles zur Regulierung der täglichen Arbeitszeit dürfte in Oberdeutschland, wie angedeutet, die Bestimmung der Arbeitspausen gewesen sein. Hier gab es häufig Streit, weil die Ordnungen wie etwa noch 1506 in Graz von dem überkommenen "ungeferlich" ausgingen und die Tagelöhner eigenmächtig die Pausen verlängerten ${ }^{60}$. Der Meister des Basler Zimmererwerks Jakob Rümelin beispielsweise hielt vor der schon erwähnten Ratskommission 1522/23 därauf, daß man die vorgeschriebenen Essenszeiten schlicht nicht einhalten könne. Er bat darum, das Morgenessen gleich dem Imbiß am Mittag auf eine Stunde auszudehnen. Überdies würde es an „allen andern orten " auch so gehandhabt ${ }^{61}$. Dies war schlicht übertrieben. Es sei dazu nur auf die recht präzisen Bauleuteordnungen in Freiburg/Br., in Salzburg, in Frankfurt und in Konstanz verwiesen 62: Auf Freiburger Baustellen wurde im Sommer die tägliche, von fünf Uhr früh bis sieben Uhr abends normierte Arbeitszeit am Morgen und am Abend durch eine halbe, während des Mittags durch eine Stunde Pause unterbrochen ${ }^{63}$. Vergleichbar genaue Regelungen wurden 1485 auch den Salzburger Maurern und Zimmerern auferlegt ${ }^{64}$. Die Steindecker Frankfurts sollten nach ihrer Satzung von 1424 mittags, „so die orglocke eilff stunde slehet... zu essen geen und wider an die erbeit sin zu der zwelfften

${ }^{59} \mathrm{Zu}$ Uhr und Arbeitszeit zuletzt: Wulf, Arbeit, 48-72 mit weiterer Literatur.

60 Fritz Popelka (Bearb.), Schriftdenkmäler des steirischen Gewerbes, Bd. 1 (Graz 1950) nr. 151: Man schrieb in Graz zur Einhaltung der wie andernorts auch saisonal gestaffelten Arbeitszeiten vor, daß den Zimmerleuten „Fruestukh und Jawsen“ auf die Baustelle, „zum Stokh oder auf das Paw", gebracht werde. Die Zimmerer konnten freilich auch zum Frühstück nach Hause, nach einer halben Stunde hatten sie wieder zur Arbeit zu erscheinen „ungeferlich“. Dazu Helmut Bräuer, Herren ihrer Arbeitszeit? Zu Organisation, Intensität und Dauer handwerklicher Arbeit in Spätmittelalter und früher Neuzeit, in: Österreichische Zeitschrift für Geschichtswissenschaften 1 (1990) 75-95, bes. 83. Schwierigkeiten mit Bauarbeitern, die eigenmächtig Frühstücks- und Vesperpausen von einer halben auf eine Stunde zu verlängern suchten, gab es 1539 auch mit Leipziger Bauleuten: Bräuer, Gesellen, $42 \mathrm{f}$.

${ }^{61}$ Staatsarchiv Basel, Bauakten A 2 (Ratskommission 1522/23).

62 Vgl. darüber hinaus: Günther Binding, Baubetrieb im Mittelalter. In Zusammenarbeit mit Gabriele Annas, Bettina Jost und Anne Schunicht (Darmstadt 1993) 137-139.

${ }^{63}$ Barbara Schock-Werner, Das Straßburger Münster im 15. Jahrhundert. Stilistische Entwicklung und Hütten-Organisation eines Bürger-Doms (Veröffentlichung der Abteilung Architektur des Kunsthistorischen Instituts der Universität zu Köln 23, Köln 1983) 29.

64 Ordnung von 1485: Arbeitszeit im Winter: 7 Uhr morgens bis 5 Uhr abends; im Sommer: 5 Uhr morgens bis 6 Uhr abends; Pausen: mittags 11 bis 12 Uhr sowie im Sommer zwei zusätzliche halbstündige Essenspausen, im Winter dagegen nur eine: Peter Michael Lipburger, „Quoniam si quis non vult operari, nec manducet..." Auffassungen von der Arbeit vor allem im Mittelalter, in: Mitteilungen der Gesellschaft für Salzburger Landeskunde 128 (1988) 4786, bes. $82 \mathrm{f}$. Leichte Veränderungen finden sich in der Salzburger Ordnung von 1524: Franz Viktor Spechtler, Rudolf Uminsky (Bearb.), Die Salzburger Stadt- und Polizeiordnung von 1524 (Göppinger Arbeiten zur Germanistik 222, Göppingen 1978) 241-244. 
stunde ane alle geverde“65. Die Frankfurter Zimmerleute- und Maurerordnungen von 1424/38 und 1498 kannten die gleichen Bestimmungen für die Mittagspause, in ihnen wurden aber ähnlich wie in Basel, Freiburg/Br. und Salzburg noch zwei halbstündige Arbeitsunterbrechungen am Morgen und am Abend aufgenommen, „das morgen- oder affterundernbroit", von jeweils einer halben Stunde. Diese Pausen waren allerdings innerhalb der Tageschronologie nicht fixiert ${ }^{66}$. Allein die Konstanzer Bauleute kannten um 1520 in den Sommermonaten (23. April bis 1. September) zumindest solche Ruhezeiten, die dem Basler Zimmerermeister Jakob Rümelin vorschwebten: Zum Morgen- wie zum Abendbrot, auch zum mittäglichen Imbiß sollten die dortigen Tagelöhner nicht „lenger dann ain stund vom werk $\sin ^{\text {“67. }}$.

Arbeitspausen wie übrigens auch die samstäglichen Badezeiten der Handwerker $^{68}$ und die Normierungen der Beschäftigungsfristen während des "guten “ oder „blauen“ Montags ${ }^{69}$ hat man also vielfach zumindest seit der Mitte des 15 . Jahrhunderts durch die Schlaguhren, aber auch noch traditionellerweise durch Sanduhren, durch die Stundengläser, präzisiert und bezeichnet ${ }^{70}$.

Pünktlichkeit und wirtschaftlich strikter genutzte Arbeitszeit ${ }^{71}$ : Sie wurden nun „sichtbarer zu bestimmenden Größen im innerbetrieblichen Verhältnis des

65 Karl Bücher, Benno Schmidt (Bearb.), Frankfurter Amts- und Zunfturkunden bis zum Jahre 1622, 2 Bde. (Veröffentlichungen der Historischen Kommission der Stadt Frankfurt a.M. VI, 1-2, Frankfurt a. M. 1914-1915; ND 1968) II, 80.

66 Bücher, Schmidt, Amts- und Zunfturkunden, II, 106, 230 (Zimmerleute allerdings ohne Morgenimbiß!).

67 Feger, Rüster, Wirtschafts- und Gewerberecht, 118, nr. 189.

${ }^{68}$ Für den engeren oberdeutschen Bereich: Ulf Dirlmeier, Untersuchungen zu Einkommensverhältnissen und Lebenshaltungskosten in oberdeutschen Städten des Spätmittelalters (Mitte 14. bis Anfang 16. Jahrhundert) (Abhandlungen der Heidelberger Akademie der Wissenschaften, phil.-hist. Kl. 1978, 1, Heidelberg 1978) 151, 153, 160-164, 176. Als Einzelbeispiel sei auf das Nümberger Bauamt verwiesen: Lexer, Weech, Tuchers Baumeisterbuch, 35, passim; Carl Ludwig Sacbs, Nürnbergs reichsstädtische Arbeiterschaft während der Amtszeit des Baumeister Michel Beheim VII. (1503-1511), in: Mittheilungen aus dem Germanischen Nationalmuseum (1914/15) 141-209, bes. 149, 155. Mit zahlreichen Beispielen aus Sachsen: Bräuer, Gesellen, 42.

69 Diese Einrichtung ist in Ansätzen seit dem frühen 14. Jahrhundert zu erkennen. Dazu Karl Koebne, Studien zur Geschichte des blauen Montags, in: Zeitschrift für Sozialwissenschaft NF 11 (1920) 268-287, 394-414; H. F. Singer, Der blaue Montag. Eine kulturgeschichtliche und soziale Studie (Mainz 1917) bes. 1-25; Rudolf Wissell, Des Alten Handwerks Recht und Gewohnheit, Bd. 2 (Berlin 21974) 415-434; Jürgen Reulecke, Blaumachen am blauen Montag, in: Diagonal. Zeitschrift der Universität-Gesamthochschule Siegen (1992) 2, 7-16; Knut Schulz, Handwerksgesellen und Lohnarbeiter. Untersuchungen zur oberrheinischen und oberdeutschen Stadtgeschichte des 14. bis 17. Jahrhunderts (Sigmaringen 1985) 172-174; Wesoly, Lehrlinge, 170-179.

70 Beispiele für Bemessung der Pausen durch Sanduhren bei: Dohrn-van Rossum, Westheider, Einführung, 326; Dobrn-van Rossum, Stunde, $277 \mathrm{f}$.

71 In Speyer war es bis 1342 noch üblich gewesen, den Tagelöhnern auf dem Bau ${ }_{w} z$ ů primen, zù vesper oder zů anderre zit" Wein zu geben. Diese Formen ritueller Entlohnung und unbestimmter Arbeitszeit sollten damals abgestellt werden: Alfred Hilgard (Bearb.), Urkunden zur Geschichte der Stadt Speyer (Straßburg 1885) 423, nr. 470. 


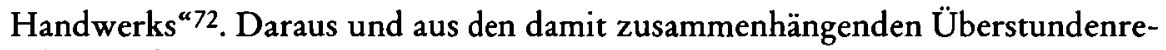
gelungen für durchgearbeitete Pausen entwickelten sich vereinzelt Vorstellungen über Stundenarbeit und über den entsprechenden Lohn: Der Tag mit seinen akustischen Normierungen von Tätigkeit und Ruhe - neben dem Stücklohn bzw. dem Verding die bisher einzige Bemessung von Arbeit - begann im Rahmen der Arbeitsorganisation durchlässiger, auch im Sinne restriktiver Maßnahmen handhabbarer zu werden ${ }^{73}$. Endres Tucher berichtet in seinem um 1464/65 entstandenen Baumeisterbuch davon, daß die städtischen Tagelöhner Nürnbergs Lohnabschläge für versäumte Stunden zu gewärtigen hatten. Für zusätzlich geleistete Arbeit, „ein stund, etzlicher zwu oder drei stund “, fanden sie in ihren samstäglichen "lönpüchslein“ freilich auch mehr Lohn vor: das sogenannte "stundgelt" ${ }^{\text {“74. }}$. Ebenso hat man beim Bau der Kirchtürme von St. Sebald in Nürnberg in den 1480 er Jahren versäumte Stunden strikt vom Lohn abgezogen, aber auch regelrechte Pausenarbeit - „under den stunden“ - zugelassen ${ }^{75}$. Wenige Jahrzehnte zuvor auf der Baustelle der Nürnberger St. Lorenz-Kirche kannte man solche Regelungen noch nicht ${ }^{76}$.

Nach der Rochlitzer Steinmetzordnung von 1462 brauchte den Gesellen, wenn sie eigenmächtig "heilige Tage" hielten, feierten und bis zum "Morgenbrot" dem Bauplatz fernblieben, das bis zum Mittag verdiente Arbeitsentgelt nicht gegeben zu werden ${ }^{77}$. In Straßburg war man da ungefähr zur gleichen Zeit schon wesentlich präziser: Wer sich von den städtischen Lohnarbeitern nicht peinlich genau an die vorgegebenen Arbeitszeiten hielt, dem sollten "sovil zeit und stunden, als er nicht gearbeitet hat, am lohne des tags" abgezogen werden "nach marzal"78. Genaueres wissen wir über die städtischen Pflasterer Straßburgs, die morgens vor Arbeitsbeginn (5 Uhr) und während der insgesamt 21/2 Stunden dauernden Pausen in den Diensten privater Auftraggeber standen. Die Stadt versuchte hier ebenfalls während der zweiten Hälfte des 15 . Jahrhunderts normierend einzugreifen, weil

72 Bräuer, Arbeitszeit, 84.

73 Frühe Beispiele vornehmlich aus Westeuropa bei: Dobrn-van Rossum, Stunde, 285-289.

${ }^{74}$ Lexer, Weech, Tuchers Baumeisterbuch, $67 \mathrm{f}$.

75 Albert Gümbel (Bearb.), Die Baurechnungen über die Erhöhung der Türme von St. Sebald in Nürnberg 1481-1495, in: Mitteilungen des Vereins für Geschichte der Stadt Nürnberg 20 (1913) 10-94, bes. 41, 57-59, 61; Valentin Groebner, Ökonomie ohne Haus. Zum Wirtschaften armer Leute in Nürnberg am Ende des 15. Jahrhunderts (Veröffentlichungen des MaxPlanck-Instituts für Geschichte 108, Göttingen 1993) 126.

76 Albert Gümbel (Bearb.), Rechnungen und Aktenstücke zur Geschichte des Chorbaus von St. Lorenz unter der Leitung Konrad Heinzelmanns, in: Repertorium für Kunstwissenschaft 32 (1909) 1-30, 132-159; ders., Baurechnungen vom Chorbau von St. Lorenz in Nürnberg 1462-1467, in: Repertorium für Kunstwissenschaft 33 (1910) 36-54, 136-154, 239-253, 339358, 443-458, 525-544; 34 (1911) 27-46, 126-146.

77 Ferdinand Janner, Die Bauhütten des Mittelalters (Leipzig 1876) 307. Formulierungen über die vom Läuten der Non abhängige sogenannte Halbtagsarbeit finden sich schon aus dem späten 13. Jahrhundert: Douglas Knoop, Gwilym Peredur Jones, The Medieval Mason. An Economic history of English Stone Building in the later Middle Ages and early Modern Times (Manchester 1933; New York ${ }^{31967)} 117$; Le Goff, Arbeitszeit, $30 \mathrm{f}$.

78 Ebeberg, Straßburg, I, 471, nr. 234. 
sich die Estricher durch ihre pausenlose Tätigkeit „vast ermüdent und helig werdent, das kein guten nützlichen tagwon der statt an irem werck getun mögent". Auch würde den Bürgern ,ir werck in der yle von handen geslagen“. Man stellte aber den Pflasterern frei, „nachtes“ nach Feierabend „clein bletzewerck“ für die Bürger zu machen, sei es nun als Verding, d.h. im Akkord ${ }^{79}$, oder aber - und bezeichnenderweise - im Stundenlohn ${ }^{80}$. Ob man damit Erfolg hatte, steht dahin. Jedenfalls hatten auch niederdeutsche Städte wie Hamburg und Lüneburg ihre Mühe damit, die an den Bauhöfen beschäftigten Lohnarbeiter zu disziplinieren und sie mit Strafen zur Einhaltung der Pausenregelungen zu zwingen ${ }^{81}$.

Aus ähnlichen ordnungspolitischen Gründen führte Nürnberg dann während der ersten Hälfte des 16. Jahrhunderts die Stundenarbeit offiziell ein - soweit wir sehen, war es die einzige oberdeutsche Stadt -, um den Bauarbeitern in Absprache mit den privaten Bauherren eine geregelte Möglichkeit zur Mehrarbeit in den Pausen zu gewährleisten ${ }^{82}$. Am Ende des 16. Jahrhunderts war in Nürnberg Stundenarbeit als „Flickwerk“, als Form der Nebenbeschäftigung von Gesellen, allgemein üblich. Die ständigen Auseinandersetzungen zwischen Meistern und Knechten über die Einhaltung der Arbeitszeiten führten jedoch 1623/58 dazu, daß die Stadt diese Möglichkeit des Zusatzverdienstes verbot, weil „kein vieh, zugeschweigen ein mensch, den ganzen tag ungerast noch ohngegessen" arbeiten könne und dies zum Nachteil der Bauherren ausschlage ${ }^{83}$.

Insgesamt also regelten in oberdeutschen Städten Schlaguhren und nach verschiedenen Kriterien ausgerichtete Glockenensembles seit der zweiten Hälfte des 14. Jahrhunderts den Rhythmus von täglicher Arbeit, Nichtarbeit und Pausenbeschäftigungen abhängiger Lohnarbeiter. Ausgesprochene Werkglocken, für Westeuropa und Oberitalien vielfach belegt und in Köln, wie gesehen, nur für das Jahr

79 Vgl. zu Akkord und Stücklohn im Baugewerbe zum Beispiel: Sachs, Arbeiterschaft, 157171.

80 Zur Regelung der städtischen Arbeit in Straßburg ordnete man an, daß sich die Privatleute an den Lohnherrn und die beiden Bauherren zu halten hätten, die dann ihrerseits die Pflasterer vom städtischen Bauhof abziehen und für diese Nebenbeschäftigungen einteilen sollten. Im Höchstfall durften allerdings nur „ein meister von dem werck, der setzen kan, und ein kneht ${ }^{\text {" }}$ ausgeliehen werden: Eheberg, Straßburg, I, 334f., nr. 134.

81 Beispiele für Hamburger (1589) und Lüneburger (1570) Statuten bei: Wulf, Arbeit, 93 f.; Eduard Bodemann (Bearb.), Die älteren Zunfturkunden der Stadt Lüneburg (Hannover 1883) $169 \mathrm{f}$.

82 Fleischmann, Bauhandwerk, $144 \mathrm{f}$. In Straßburg holte man 1556, nachdem das Baugewerbe immer dringlicher auf eine Erhöhung der veralteten Tariflöhne gedrängt hatte, ein Gutachten der Werkmeister ein, in dem die Umstellung vom Tage- auf den Stundenlohn diskutiert wurde. Die Werkmeister sahen im Stundenlohn positive Aspekte sowohl für die Handwerker als auch für die Bauherren. Den einen brächte die stundenweise Bezahlung eine leichte Lohnerhöhung, den anderen eine höhere Arbeitsleistung. Dieser Vorschlag wurde vom Stadtrat verworfen und eine Anpassung der Tagelöhne vorgenommen: Scbulz, Handwerksgesellen, 335 .

${ }_{83}$ Zitat nach: Bruno Schoenlank, Zur Geschichte altnürnbergischen Gesellenwesens, in: Jahrbücher für Nationalökonomie und Statistik 53 (1889) 337-395, 588-615, bes. 347; Bräuer, Arbeitszeit, 87; Fleischmann, Bauhandwerk, 145 (mit einer Quelle bereits von 1623). 
1374 bezeugt, waren dagegen in den Städten Oberdeutschlands sehr selten ${ }^{84}$, sie wurden im deutschsprachigen Raum vornehmlich im außerstädtischen Bereich des Bergbaus verwendet ${ }^{85}$. Dies hing höchstwahrscheinlich damit zusammen, daß innerhalb der oberdeutschen Stadtökonomien einzelne Gewerbe weniger dominant waren als beispielsweise die im Großverlag betriebenen Weber- und Färberindustrien in Brügge und Florenz $z^{86}$. Dort freilich, wo wie in Würzburg und Konstanz, vermutlich auch in Basel, eine bestimmte Zunft überproportional zahlreich vertreten war bzw. verhältnismäßig viele Lohnarbeiter benötigte, hat man auch ein den Werkglocken vergleichbares Signalensemble geschaffen, ein spezielles akustisches System zur Normierung der Leistung einer gesonderten Beschäftigtengruppe verwendet. In Würzburg, Konstanz und Basel riefen Glocken im jahreszeitlichen Wechsel Tagelöhner zu Ausbesserungs-, Schneide-, Hack-, Umgrabe-, Jät-, Binde-, Laubschneide-, Düngungs- und Lesearbeiten in die Weinberge $^{87}$.

${ }^{84}$ In der Frankfurter Zimmerleuteordnung von 1424/38 zum Beispiel wird die Glocke „zu sant Niclas" dazu bestimmt, den Beginn und das Ende des Arbeitstages zu markieren: Bücher, Schmidt, Amts- und Zunfturkunden, II, 230. In Aachen gab es im Spätmittelalter eine "Werkglocke“, die Arbeitsbeginn und -ende anzeigte: Harry Kübnel, Zeitbegriff und Zeitmessung, in: Alltag im Spätmittelalter, 9-16, bes. 12. Im Jahre 1366 hat die Stadt Regensburg eine Arbeitsglocke aufhängen lassen: Hermann Heimpel, Das Gewerbe der Stadt Regensburg im Mittelalter. Mit einem Beitrag von Franz Bastian, Die Textilgewerbe, in: Vierteljahrschrift für Sozial- und Wirtschaftsgeschichte 9 (Stuttgart 1926) 292.

85 Der Schichtwechsel im Bergwerk fand nach Georg Agricola beim „Läuten einer großen Glocke" statt: Carl Schiffner (Bearb.), Georg Agricola. Zwölf Bücher vom Berg- und Hüttenwesen (Düsseldorf ${ }^{3} 1961$, ND 1994) 77f. Dazu Gustav Klemens Schmelzeisen, Die Arbeitsordnung in den jüngeren Berggesetzen, in: Zeitschrift der Savigny-Stiftung für Rechtsgeschichte GA 72 (1955) 111-153, bes. 134-136; Schreiner, Diversitas Temporum, $397 \mathrm{f}$.

86 Belege zu Werkglocken bei: Dohrn-van Rossum, Stunde, 273-275. Schon Fagniez hat darauf hingewiesen, daß in Städten wie Paris mit einer verhältnismäßig ausgeglichenen Gewerbestruktur Werkglocken fehlten: Gustave Fagniez, Études sur l'Industrie et la Classe industrielle à Paris au XIII' et XIVe siècle (Paris 1877; ND 1975) 84. Zum Tuchverlag zuletzt: Rudolf Holbach, Frühformen von Verlag und Großbetrieb in der gewerblichen Produktion (13.-16. Jahrhundert), in: Vierteljahrschrift für Sozial- und Wirtschaftsgeschichte 110 (Stuttgart 1994) 47-208.

${ }_{87}$ Entscheidend dabei war offensichtlich nicht die zahlenmäßige Zunftstärke. In Würzburg sind die eigentlichen Weingartenbesitzer 1441/55 von ihrer Zahl her nur im unteren Mittelfeld der Zünfte zu finden. Die vom Reb- und Gartenbau abhängigen Hecker, Tagelöhner und Büttner waren aber nach den Untersuchungen von Götz (16. Jahrhundert) dort ebenso zahlreich und arm wie am Oberrhein: Hermann Hoffmann, Würzburgs Handel und Verkehr im Mittelalter. I. Allgemeiner Teil (Kallmünz o.J. 1940) 194; Hannelore Götz, Würzburg im 16. Jahrhundert. Bürgerliche Vermögen und städtische Führungsschichten zwischen Bauernkrieg und fürstbischöflichem Absolutismus (Veröffentlichungen des Stadtarchivs Würzburg 2, Würzburg 1986) 126-130, 137-141. Zu den zahlenmäßig bedeutenden Bauern-, Gärtnerund Rebleutezünften auch in größeren oberdeutschen Städten: Karl Bücher, Die Bevölkerung von Frankfurt am Main im XIV. und XV. Jahrhundert. Socialstatistische Studien (Tübingen 1896) bes. 259-293; Paul Koelner, Die Rebleutenzunft zu Basel (Basel 1942); Schulz, Handwerksgesellen, 37-46. Zu den verschiedenen Weinbergsarbeiten und zur Lage der Lohnarbeiter/-innen im spätmittelalterlichen Weinbau: Scbulz, Handwerksgesellen, 343361; Peter Feldbauer, Lohnarbeit im österreichischen Weinbau. Zur sozialen Lage der nieder- 
Würzburg war im Spätmittelalter vom Weinbau geprägt. Agostino Patrizzi, der im Gefolge des Kardinals Francesco Todeschini-Piccolomini 1471 die Stadt besuchte, konnte hier nur mit einigem Abscheu die Ausdünstungen gedüngter Weinberge registrieren ${ }^{88}$. Bereits $1341 / 42$ verordneten Bischof und Rat, „daz man des morgens frú sol lưten die glocken zů grefen Eckeharten“. Nach dem Glockenschlag dieser sogenannten Heckerglocke auf dem Grafeneckart, einem 1316 von der Stadt erworbenen und als Rathaus umgebauten befestigten Turmsitz des bischöflichen Schultheißen und Burggrafen ${ }^{89}$, hatte jeder Weingartenbesitzer die Hecker, Schnitter oder Binder an bestimmten "mytsteten “, wie es 1376 heißt, zu dingen und seine Tagwerker, wann die Glocke „zu dem andern mole lutet“, hinaus in die Weinberge zu führen. Am Abend zeigte "dieselbe glocke“ den Arbeitsschluß an. Die Tagelöhner hatten dieses Feierabendläuten jenseits des Mains „an der brucken“ abzuwarten und durften erst dann in ihre städtischen Behausungen zurückkehren90. Ähnliche Maßnahmen kannte man in Erfurt allerdings nur bei Arbeitsmarktkrisen: Als beispielsweise 1497 bei der dortigen Weinlese nur wenige Arbeiter zu finden waren und sich die Weingartenbesitzer die Tagelöhner gegenseitig mit hohen Löhnen abzuwerben versuchten, schritt der Rat ein, setzte Höchstlöhne fest und verhinderte durch rigoroses Vorgehen gegen Lohnbrecher alle unerwünschte Konkurrenz. Man ließ auch alle Stadttore am Abend nicht früher aufschließen, „es hette danne sechsse geslagen“. Denn die Tagelöhner „nomen sich an und lieffen czitlich von der arbeit" $"$.

österreichischen Weingartenarbeiter des Mittelalters und der frühen Neuzeit, in: Zeitschrift für bayerische Landesgeschichte 38 (1975) 227-243, bes. 232-239; Lukas Clemens, Trier Eine Weinstadt im Mittelalter (Trierer Historische Forschungen 22, Trier 1993) 258-274, 282-309.

88 Die Beschreibung Patrizzis von der Rückreise der Gesandtschaft des Kardinals Francesco Todeschini-Piccolomini (Reichstag Regensburg-Rom) ist vollständig ediert bei: Frank-Rutger Hausmann, Giovanni Antonio Campano (1429-1477). Erläuterungen und Ergänzungen zu seinen Briefen (Diss., Freiburg/Br. 1968, Maschr.) 533-575, bes. 542. Dazu Klaus Voigt, Italienische Berichte aus dem spätmittelalterlichen Deutschland. Von Francesco Petrarca zu Andrea de' Franceschi (1333-1492) (Kieler Historische Studien 17, Stuttgart 1973) 160-171. 89 Zur Geschichte des Hofes „Zum Grafeneckart“: Franz Xaver Wegele, Der Hof zum Grafen-Eckard zu Wirzburg und Graf Eckard (Würzburg 1860) bes. $16 \mathrm{f}$.; Winfried Schich, Würzburg im Mittelalter. Studien zum Verhältnis von Topographie und Bevölkerungsstruktur (Städteforschung A, 3, Köln, Wien 1977) $103 \mathrm{f}$.

90 Hermann Hoffmann (Bearb.), Würzburger Polizeisätze, Gebote und Ordnungen des Mittelalters, 1125-1495. Ausgewählte Texte (Veröffentlichungen der Gesellschaft für fränkische Geschichte X, 5, Würzburg 1955) 57, nr. 71 (1341/42); 77, nr. 114f. (1376); 90, nr. 208 (1387). 91 Thiele, Stolle, 463, nr. 361. Demgegenüber zeigt der Schwank vom Pfarrer zu Kahlenberg, wie sehr die Arbeiter im Weinberg vom Willen dessen abhängen konnten, der sie auf mietstat gedingt hatte. Der Pfarrer zahlte ihnen am ersten Tag nicht den vollen Lohn aus. Als die Hauer daraufhin am nächsten Tag schon zu Mittag nach Hause gingen, zwang sie der Kahlenberger, am folgenden Tag bis in die Nacht zu arbeiten: Viktor Dollmayr (Bearb.), Philipp Frankfurter. Die Geschichte des Pfarrers vom Kahlenberg (Neudrucke deutscher Literaturwerke 212-214, Halle 1906) 15-20, vv. 297-398; Emst Schubert, Soziale Randgruppen und Bevölkerungsentwicklung im Mittelalter, in: Saeculum 39 (1988) 294-339, bes. 309. 
Seit dem Jahre 1387 hatten sich in Würzburg die Benennungen für die täglichen Glockenrufe geändert: Die Heckerglocke mit ihrem zweimaligen morgendlichen Geläut wurde nun entsprechend ihrem Unterbringungsort im Rathaus als „rotglocken" bezeichnet, ihr abendliches Gegenstück als "betglokken"92. Wahrscheinlich hat man die für die Hecker spezialisierte Glocke dem allgemeinen akustischen Kommunikationssystem der Stadt angepaßt. Jedenfalls sollte nun der morgendliche Ruf der Hecker- oder Ratsglocke nicht nur die Arbeitszeit festlegen, sondern auch den Arbeitsmarkt als öffentlich-kontrollierte Einrichtung bezeichnen, ihn damit beschränken und ein einheitliches Lohnniveau schaffen. Denn wer Arbeiter nach dem zweiten Läuten oder an anderen Plätzen rekrutierte, hatte mit einer Strafe zu rechnen. Überdies durfte niemand einen Tagwerker, der „versitzet biz nach der glocken“, anwerben, womöglich noch zu einem höheren Lohnsatz.

Ob diese Regelungen fein säuberlich beachtet wurden, steht bei ihren häufigen Wiederholungen dahin ${ }^{93}$. Immerhin kannte auch Basel für seine Rebleute sehr ähnliche Arbeitsmarktordnungen: Dort bezeichnete wahrscheinlich die sogenannte Tagglocke den morgendlichen Arbeitsbeginn der Tagelöhner im Weinbau ${ }^{94}$. In Konstanz hat man sogar Arbeitsglocken an zwei verschiedenen Orten, auf dem Kreuzlinger Turm und jenseits des Rheins zu Petershausen, aufgehängt, um damit das weit auseinanderliegende Rebgelände besser beschallen zu können. Die Konstanzer Rebleuteglocken riefen nach einer Ratsordnung des Jahres 1540 die Tagelöhner, darunter sehr viele Frauen, nur von Mitte Mai bis August zur Arbeit, mit ihnen regelte man auch die Pausenzeiten der vor den Toren der Stadt tätigen Menschen: Wenn die Glocke nach dem Morgensignal „widerumb lüt, das bschehe, zu welher zit im tag es welle, so sollend alle, die in reben sind, uffhören werken und kain werk mer darin tun, biß das man die glogken widerumb lütet" ${ }^{\text {"95 }}$.

In Würzburg ließ übrigens der Dompropst die Weinlese durch besondere Glocken einläuten und damit den je nach Reifegrad der Trauben herrschaftlich

92 Hoffmann, Polizeisätze, 90 f., nr. 209.

93 Das Verbot unredlicher Anwerbungen von Tagelöhnern wurde während des Spätmittelalters zuletzt 1434 eingeschärft: Hoffmann, Polizeisätze, 119, nr. 292.

94 Mit Sonnenaufgang (Tagglocke) hatten sich in Basel die Rebleute an einem bestimmten Rekrutierungsplatz einzufinden. Es war verboten, schon vorher an einem anderen Ort Tagelöhner zu dingen: Koelner, Rebleutenzunft, 23. Auch in Metz und Eßlingen kannte man nach Verordnungen von 1355 bzw. 1431 öffentliche Plätze zur Anwerbung der in den Weingärten tätigen Männer, Frauen und Kinder, in Metz überdies ein Signalsystem, bestehend aus den Glocken mehrerer Stadtkirchen, zur Festlegung ihrer Arbeitszeit. Zu Metz: Jean François, Nicolas Tabouillot (Bearb.), Histoire générale de Metz par des religieux bénédictines de la congrégation de Saint Vannes, 7 Bde. (Metz 1768-1790, ND Paris 1970) IV, 160 f. Für diesen wie andere Hinweise zu Metz danke ich Herrn Alexander Reverchon, Trier. Zu Eßlingen: Schubert, Soziale Randgruppen, 309.

${ }^{95}$ Feger, Rüster, Wirtschafts- und Gewerberecht, 45, nr. 42; 179, nr. 330. Zur Weinbergsarbeit der Frauen in Konstanzer Tagelöhnerhaushalten sei auf die Enquête Hans Berners von 1531 verwiesen: Otto Winckelmann, Das Fürsorgewesen der Stadt Strassburg vor und nach der Reformation bis zum Ausgang des sechzehnten Jahrhunderts, 2 Tle. (Quellen und Forschungen zur Reformationsgeschichte 5, Leipzig 1922, ND 1971), II, 278. 
festgelegten Beginn der Erntearbeiten offiziell kundtun" ${ }^{96}$. Natürliche Gegebenheiten, Ökonomie, öffentliche Ordnung und Glocke spiegelten sich in Würzburg auch in einem anderen Ereigniszusammenhang wider: Im Mai 1492 hat man wegen großen Frostes acht Tage lang „zu morgens umb 2 oder 3 uhren, da der frost und reyf herging, mit allen glockhen... ein gantze stundt" lang läuten lassen - die Glocken als Zeichen von Bitte und Gebet, die Wetterglocken mit ihrer apotropäischen Symbolik, aufgeboten als mythische Zeichen, um das Wohlergehen eines der wichtigen Würzburger Produktionszweige zu sichern ${ }^{97}$.

\section{Zeit, Konkurrenz und Ordnung: die städtischen Handwerke und Gewerbe}

Die Arbeits- und Pausenzeiten besonders der Bauhandwerker und der Tagelöhner innerhalb der städtischen Wein- und Gartenkulturen wurden mit Hilfe von Uhr und Glocke seit der zweiten Hälfte des 14. Jahrhunderts eng begrenzt, auch um den Anbietern von Arbeit, privaten wie öffentlichen Bauherren und Arbeitgebern, Kontrollmöglichkeiten einzuräumen. Es galt Menschen zu kontrollieren, die einen eigenen Hausstand besaßen, nicht zum Haushalt der Arbeitsbesitzer gehörten, nicht in die vom Gang des Lebens im meisterlichen Betrieb „bestimmte ,allgemeine' Zeit der Familie“ eingefügt waren - die Arbeitszeit von Lehrlingen und Gesellen orientierte sich an den Gepflogenheiten des Meisterhaushalts, Gesindearbeit war im Grunde unbemessen, richtete sich nach dem jeweiligen Arbeitsanfall ${ }^{98}$. Es galt darüber hinaus eine individuelle Leistung zu bewerten, die vornehmlich nicht in Form von Akkord oder Stücklohn, sondern pro Zeiteinheit erbracht wurde. Den städtischen Ratskollegien eröffnete jene Präzisierung und Standardisierung von Arbeitsleistung via akustischer Kommunikation auf ihrem

96 Dazu die 1484 (X 7), 1501 (o.D.), 1503 (X 31) und 1520 (X 17) durch Einläuten festgelegten Lesetermine bei: Wilhelm Engel (Bearb.), Die Rats-Chronik der Stadt Würzburg (XV. und XVI. Jahrhundert) (Quellen und Forschungen zur Geschichte des Bistums und Hochstifts Würzburg 2, Würzburg 1950) 44, nr. 138; 64, nr. 194; 81, nr. 256; 83, nr. 268. Auch andernorts bezeichneten Glocken den Bereich von städtischer Herrschaft und Sicherheit: Das Duisburger Stadtrecht von 1518 zum Beispiel sah für den Fall, daß man die abgeernteten Kornfelder beweidete und ein Unwetter aufzog, die Alarmierung der Viehhirten mit einer Glocke vor. Die Erlaubnis zur Eichelmast im Stadtwald sollte unter dem Läuten der Rathausglocke bekanntgegeben werden: Arend Mibm, Michael Elmentaler (Bearb.), Das Duisburger Stadtrecht 1518 (Duisburg 1990) 190, 202.

97 Engel, Rats-Chronik, 51, nr. 151. Zu Wetterglocken: Leo Zebnder, Volkskundliches in der älteren schweizerischen Chronistik (Schriften der Schweizerischen Gesellschaft für Volkskunde 60, Basel 1976) 199.

98 Bräuer, Arbeitszeit, 86. Zur Situation des Gesindes: Otto Könnecke, Rechtsgeschichte des Gesindes in West- und Süddeutschland (Marburg 1912; ND 1970); Johann Kamann, Altnürnberger Gesindewesen, in: Mitteilungen des Vereins für Geschichte der Stadt Nürnberg 14 (1901) 65-157. 
Weg zur Obrigkeit, den sie seit den letzten Jahrzehnten des 15. Jahrhunderts gingen, zugleich die Chance, normierend im Sinne von Herrschaft auf einen beträchtlichen Teil des städtischen Arbeitsmarktes zuzugreifen.

Anders stand es um die zünftig geregelte, hauptsächlich in den handwerklichen Kleinbetrieben der Meisterhaushalte vollbrachte Arbeit ${ }^{99}$. Arbeitszeitnormierungen zum Vorteil von potentiellen Kunden und Arbeitgebern brauchte es hier im Grunde nicht. Das Preiswerk beherrschte die Produktionsweise in den führenden Handwerken und Gewerben größerer Städte, damit waren - theoretisch zumindest - der Selbst- und Fremdausbeutung von Arbeitskraft und -zeit keine Grenzen gesetzt. In den Branchen, wo dagegen das Lohnwerk vorherrschte, arbeiteten die Handwerker im Stücklohn entweder in ihrem eigenen Hause oder im Haushalt des Kunden (auf der Stör) und damit unter dessen unmittelbarer Kontrolle ${ }^{100}$.

Arbeitszeitfestsetzungen innerhalb der spätmittelalterlichen Zünfte waren dennoch allgemein und nahezu ausnahmslos verbreitet ${ }^{101}$. Sie sollten, betrachtet aus der Innenperspektive des Handwerks, bei Exportwaren zur Stabilisierung der Qualität dienen, vor allem aber gleiche Chancen für alle Zunftgenossen sichern, die zünftige "Ökonomie des Überlebens", das Nahrungsprinzip garantieren ${ }^{102}$. So gab es selbst in dem von den Gewohnheiten des privaten Haushalts bestimmten Bereich des Lohnwerks seit dem späten 15. Jahrhundert Zeitregelungen: Beispielsweise sollten 1490 in Villingen Schneider auf der Stör im Sommerhalbjahr „am morgen [erst] zwüschent fünfen und sechsen in des kunden hus gon und am abend umb die achte widerumb darus" 103 . Die Konstanzer Schneider durften ihre Kunden während des Winters nur bis abends, "wan es nüne schlacht", aufsu-

$99 \mathrm{Zu}$ der im deutschsprachigen Raum trotz einiger Ansätze zur großgewerblichen Produktion besonders im Metallbereich vorherrschenden kleinbetrieblichen Struktur in Handwerk und Gewerbe: Eberhard Isenmann, Die deutsche Stadt im Spätmittealter. 1250-1500. Stadtgestalt, Recht, Stadtregiment, Kirche, Gesellschaft, Wirtschaft (Stuttgart 1988) 341-356. Zur Okonomie des Meisterhauses zum Beispiel: Wilfried Reininghaus, Das "ganze Haus" und die Gesellengilden. Über die Beziehungen zwischen Meistern und Gesellen im Spätmittelalter, in: Rainer S. Elkar (Hrsg.), Deutsches Handwerk in Spätmittelalter und Früher Neuzeit. Sozialgeschichte - Volkskunde - Literaturgeschichte (Göttinger Beiträge zur Wirtschaftsund Sozialgeschichte 9, Göttingen 1983) 55-70.

$100 \mathrm{Vgl}$. dazu exemplarisch, allerdings mit den typischen anachronistischen, entwicklungsgeschichtlichen Konstrukten der "Jüngeren historischen Schule der Nationalökonomie ${ }^{\alpha}:$ Karl Bücher, Die gewerblichen Betriebssysteme in ihrer geschichtlichen Entwicklung, in: ders., Die Entstehung der Volkswirtschaft. Vorträge und Aufsätze. Erste Sammlung (Tübingen 1519/20) 161-196.

101 Reinald Ennen, Zünfte und Wettbewerb. Möglichkeiten und Grenzen zünftlerischer Wettbewerbsbeschränkungen im städtischen Handel und Gewerbe des Spätmittelalters (Neue Wirtschaftsgeschichte 3, Köln, Wien 1971) 36-39: Ennen nennt als Ausnahme das Privileg des Kölner Rats für die Nadelmacher von 1507. Danach sollte die Dauer der Arbeitszeit im Ermessen der Meister liegen (38).

102 Zitat: Michael Stürmer, Herbst des alten Handwerks. Meister, Gesellen und Obrigkeit im 18. Jahrhundert (München 1979; ND 1986) 107. Dazu Ennen, Zeitbewußtsein, 96.

$103 \mathrm{Im}$ Winter von 6 Uhr morgens bis 9 Uhr abends: Christian Roder (Bearb.), Villingen (Oberrheinische Stadtrechte II, 1, Heidelberg 1905) 104, nr. 35. 
chen ${ }^{104}$. Aus der Außensicht der städtischen Räte dagegen überwogen bei den Normierungen gerade der zünftigen Nachtarbeit ordnungspolitische Zielsetzungen: Die bei der vorherrschenden Holzbauweise selbst größerer Städte ungeheuere Feuergefahr sollte eingedämmt, als lästig betrachtete Immissionen verschiedener Art vermieden werden. Durch die Verbote von Sonn- und Feiertagsarbeit versuchte man überdies, der allgemeinen kirchlichen Feiertagsheiligung wie dem Ruhebedürfnis der Stadtbewohner nachzukommen. Sperrstundenfristen, vermittelt durch Glockensignale, schalteten Konkurrenzen im Wirtsgewerbe aus, die Glocken, welche die absolute Nachtruhe geboten, zeigten die sicherheits- und ordnungspolitischen, schließlich auch die moralischen und sozialpolitischen Vorstellungen spätmittelalterlicher Stadträte an. $\mathrm{Zu}$ den genannten drei Komplexen sind zahlreiche Quellen vorhanden. Eine Auswahl davon soll in den folgenden, getrennten Untersuchungsschritten vorgestellt und besprochen werden.

Zum ersten Aspekt - städtische Zeit und zünftige Konkurrenz. Hier bieten zunächst gerade die Kölner Zunftsatzungen eingehende Regelungen: Schon 1230 unterstellte Erzbischof Heinrich von Molenark die Deutzer Wollenweber der Aufsicht des Kölner Wollenamts, wobei die Fristen für Beginn und Ende der täglichen Arbeit in beiden Städten gleich sein, Wettbewerbsverzerrungen also vermieden werden sollten ${ }^{105}$. In der zwischen 1370 und 1397 überlieferten Amtsordnung der Kölner Garnmacherinnen, eine Art Vorstufe zum Zunftbrief, wurde der mor-

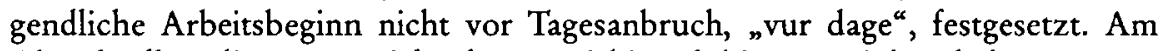
Abend sollten die Frauen nicht "langer wirkin “ als bis zum Einbruch der Dämmerung „of zo 8 uren" ${ }^{106}$. Das Prinzip für Vermeidung von Konkurrenz wurde hier also schon um die Kategorie "Qualität der Arbeit" erweitert. Denn die Produktionsbedingungen bei der verwendeten Talg- und Unschlittbeleuchtung waren alles andere als günstig ${ }^{107}$. Freilich, als es nach dem durch den Verbundbrief von 1396 markierten Ende der Kölner Wirren ${ }^{108}$ im Jahre 1397 zu einer Flut von Amtsbrie-

104 1502/15: vom 23.4. bis 29.9.: 5-6 Uhr morgens bis 7 Uhr abends; vom 29.9. bis 23.4.: 6-7 Uhr morgens bis 9 Uhr abends: Feger, Rüster, Wirtschafts- und Gewerberecht, 132, nr. 208. 105 "Cessabunt etiam dicti cives nostri Tuicienses prefati operis ab exercitio lanei operis, quando Colonienses communiter duxerint opus laneum deponendum; et Tuitienses idem opus non resument donec Colonienses id resumpserint ${ }^{\text {" }}$ : Loesch, Zunfturkunden, II, 478, nr. 731.

106 Loesch, Zunfturkunden, II, 154, nr. 377. Zu den Kölner Garnmacherinnen: Margret Wensky, Die Stellung der Frau in der stadtkölnischen Wirtschaft im Spätmittelalter (Quellen und Darstellungen zur hansischen Geschichte NF 26, Köln, Wien 1980) 61-71. Zur Kölner Wirtschaft insgesamt: Franz Irsigler, Die wirtschaftliche Stellung der Stadt Köln im 14. und 15. Jahrhundert, in: Vierteljahrschrift für Sozial- und Wirtschaftsgeschichte 65 (Wiesbaden 1979).

107 Zum Zusammenhang Arbeitszeit und Warenqualität: Lawrence Abbott, Qualität und Wettbewerb. Ein Beitrag zur Wirtschaftstheorie (München, Berlin 1958); Gerbard Jaritz, Handwerkliche Produktion und Qualität im Spätmittelalter, in: Handwerk und Sachkultur, 33-49, bes. 43 (Nachtarbeit); Ennen, Zünfte, 59-65; Wulf, Arbeit, 75-78.

108 Klaus Militzer, Ursachen und Folgen der innerstädtischen Auseinandersetzungen in Köln in der zweiten Hälfte des 14. Jahrhunderts (Veröffentlichungen des Kölner Geschichtsvereins 36, Köln 1980). 
fen kam und der Rat auch den Garnmacherinnen ihre Ordnung bestätigte, zog man sich offiziell auf ein allgemeinmenschliches Motiv zurück: Die Zeitordnung sei „gemacht, umb der natur unrasten wille zo verhueden “. Die Arbeitszeit wurde interessanterweise nicht mehr durch den morgendlichen Rhythmus des Lichttages und die um 1370 noch völlig neue städtische Uhr begrenzt, sondern richtete sich nun ausschließlich nach dem Geläut Kölner Glocken: Die Glocken, die zur "doimmetten“, zu der missa matutina, riefen, zeigten morgens den Beginn der täglichen Mühe an, die „nachtklocke“ beendete den Arbeitstag ${ }^{109}$.

Auch andernorts war dies so: Den Nürnberger Köhlern und Schmieden gebot die "feurglogge" den Feierabend 110 , die Fischer im elsässischen Schlettstadt fuhren 1388 nach dem 8. September hinaus, "wenne man die meßeglocken angezuhet $^{\prime 111}$, und in dem kleinen Isny galt 1464 generell die Vorschrift, daß „iederman mit sim werk sol ufhören, so man firaubent lut ${ }^{\star 112}$.

In den allesamt 1397 erlassenen Amtsbriefen der Kölner Harnischmacher (5 a.m. bis 9 Uhr p.m. $)^{113}$, der Schreiner (4 a.m. bis 8 Uhr p.m.) und der Nadelmacher $(5 \text { a.m. bis } 8 \mathrm{Uhr} \text { p.m.) })^{114}$ dagegen wurden unabhängig vom Lichttag genaue und das ganze Jahr über gleichbleibende Uhrzeiten zur Begrenzung der täglichen Arbeit vorgezogen. Bei den Schmieden ( 5 a.m. bis 8 Uhr p.m.) und Taschenmachern ( 5 a.m. bis 9 Uhr p.m.) hat man die Arbeitszeit im Winterhalbjahr mit Uhrzeiten normiert, in den Sommermonaten galt dagegen wohl der Lichttag ${ }^{115}$. Bei den Barchentwebern Kölns setzten um 1393 noch die neuartigen Uhrzeiten Grenzen, seit 1420 bestimmte dann wieder der Lichttag, des Tages "up- ind afgain“, die Arbeit am Webstuhl ${ }^{116}$. Bezeichnend für das zünftige Nahrungsprinzip ist dabei, daß sich die Leinenweber, deren Handwerk an der öffentlichen Uhr orientiert war (5 a.m. bis 8 Uhr p.m.), an die Zeitordnung der Barchentzunft halten mußten, wenn sie „sardoich“, also Barchent, weben wollten ${ }^{117}$.

Während des ganzen Spätmittelalters gab es nun Versuche der Meister, diese sich mehr oder minder am Lichttag orientierenden und mit Hilfe von Uhr und Glocken bezeichneten zünftigen Arbeitszeitregelungen zu durchbrechen. Die Be-

${ }^{109}$ Loesch, Zunfturkunden, I, 50, nr. 22. Die Kölner Kannengießer kannten dieselben Glokkensignale für ihre Arbeitszeiten: ebd. I, $116 \mathrm{f}$., nr. 41.

110 Baader, Polizeiordnungen, 159; Schulthei $\beta$, Satzungsbücher, I, 126 (morgendlicher Arbeitsbeginn: das Matutin-Geläut).

111 Joseph Gény (Bearb.), Schlettstadter Stadtrecht, 2 Tle. (Oberrheinische Stadtrechte III, 12, Heidelberg 1902) II, 545, 1. Dazu Melchior Mayer, Die Lebensmittel-Politik der Reichsstadt Schlettstadt bis zum Beginn der Französischen Herrschaft (Phil. Diss. Freiburg/Br. 1907) 131.

112 Und die Krämer sollten schließen, „so man zámen luit“: Karl Otto Müller (Bearb.), Die älteren Stadtrechte von Leutkirch und Isny (Württembergische Geschichtsquellen 18: Oberschwäbische Stadtrechte 1, Stuttgart 1914) 258.

113 Sie kannten bereits 1391 die gleichen Uhrzeitregelungen: Loesch, Zunfturkunden, I, $103 \mathrm{f} .$, nr. 34; $105 \mathrm{f}$., nr. 36.

114 Loesch, Zunfturkunden, I, 143, nr. 53 (Nadelmacher); 159, nr. 59 (Schreiner).

115 Loesch, Zunfturkunden, I, 155, nr. 56 (Schmiede); 182, nr. 70 (Taschenmacher).

116 Loesch, Zunfturkunden, I, 149, nr. 54; II, 363, nr. 582.

117 Loesch, Zunfturkunden, I, 149, nr. 54. 
mühungen richteten sich insbesondere darauf, die Feierabendgrenze weit in die Nacht hinein zu verschieben, zum Nachteil vor allem der Gesellen, die dadurch Einschnitte in ihr Zeitbudget für das notwendige Zubrot der Flick- und Reparaturarbeiten sowie bei gleichbleibenden Tagelöhnen eine faktische Lohnminderung in Kauf zu nehmen hatten ${ }^{118}$. Ein extremes Beispiel für diese durch branchenspezifische Niedriglöhne, Mangel, aber auch durch Auftrags- und Marktdruck charakterisierte Entwicklung bieten die Krakauer Schneider, die 1390 ihre Arbeitszeit „bis czu mitternacht" verlängerten ${ }^{119}$. Die Stadträte und Zünfte schritten dagegen nur teilweise ein: In einer der frühen Ordnungen für die Kölner Tuchscherer von 1293 wurde zwar das Scheren "mit lithe" im Dezember unter Strafe gestellt, in den Winterwochen danach aber an eine bemessene Tuchgröße gebunden. Zunftmeister und Rat konnten allerdings von diesen Beschränkungen dispensieren ${ }^{120}$. Ausdrücklich erlaubt wurde dagegen das Arbeiten über die Feierabendglocke hinaus beispielsweise 1395 den Straßburger Küfern (Bedeutung des Weinhandels!) und 1397 den Kölner Nadel-, Gürtel- und Taschenmachern - allerdings nur während des Winters, in den Sommermonaten blieb dies verboten ${ }^{121}$. Die Kölner Filzhutmacher freilich durften sogar das ganze Jahr über „bis zein uren“ fleißig sein ${ }^{122}$.

Generelle bzw. auf die langen Abende der Winterszeit beschränkte Nachtarbeitsverbote kannten indes, bezeichnend für eine auf den Export angelegte $\mathrm{Ge}$ werbestadt, nur wenige Kölner Handwerke wie die Kupferschläger und Wollenweber ${ }^{123}$. Auch den Straßburger Tuchern und Frankfurter Barchentwebern wurde um 1430 eine allgemeine Nachtruhe auferlegt. In Frankfurt hat man 1507 das Verbot für die Monate September bis Februar allerdings "gemiltiget“: Die Weber durften morgens um fünf Uhr anfangen und abends, „biß man die wynglock ludet", arbeiten, also über den allgemeinen Arbeitsschluß hinaus bis zur Sperrstunde $^{124}$. Für die Schlettstadter Fischer wurden 1388 Nachtfangverbote erlas-

118 Bräuer, Arbeitszeit, $87 \mathrm{f}$.

119 Bruno Bucher (Bearb.), Die alten Zunft- und Verkehrsordnungen der Stadt Krakau (Wien 1889) 97. Dazu auch Bräuer, Gesellen, 43.

120 Loesch, Zunfturkunden, I, 190, nr. 73.

121 Zu den Straßburger Küfern: Johann Karl Brucker (Bearb.), Straßburger Zunft- und Polizei-Verordnungen des 14. und 15. Jahrhunderts (Straßburg 1889) 318. Zu Köln: Loesch, Zunfturkunden, I, 97, nr. 31; 99 f., nr. 32 (Gürtelmacher: kannten 1371/96 noch die 10 UhrRegelungen, die abendliche Arbeitszeit wurde 1397 auf 9 Uhr reduziert; Lichtarbeit war nur während des Winters erlaubt); 143, nr. 53 (Nadelmacher); 182, nr. 70 (Taschenmacher: abendliche Arbeitszeit bis 9 Uhr; Lichtarbeit nur während des Winters).

122 Loesch, Zunfturkunden, I, 113, nr. 39 (Filzhutmacher, allerdings mit der Einschränkung, an den Vorabenden von Feiertagen nicht mit Licht zu arbeiten).

123 Loesch, Zunfturkunden, I, 120, nr. 43 (Kupferschläger, 1421: abendliche Arbeitszeit bis 8 Uhr; das Bedienungspersonal an Bälgen und Öfen durfte länger arbeiten; im Winter Lichtarbeit verboten); 203, nr. 78 (Wollenamt, 1397 mit der Androhung des Verlusts der Zünftigkeit!).

124 Bücher, Schmidt, Amts- und Zunfturkunden, I, $301 \mathrm{f}$. Zu Straßburg: Gustav Schmoller, Die Straßburger Tucher- und Weberzunft. Urkunden und Darstellung. Ein Beitrag zur Geschichte der deutschen Weberei und des deutschen Gewerberechts vom XIII.-XVII. Jahrhundert (Straßburg 1879) 30, nr. 23; 65, nr. 28. 
$\operatorname{sen}^{125}$. Doch auch bei diesen restriktiven Regelungen gab es bezeichnende Ausnahmen. So durften die Kölner Goldschmiede und Goldschläger im Winterhalbjahr nicht länger mit Kerzen arbeiten „dan bis nachtlichzijt, as man zo s. Laurencius ind s. Albaen geluit hait". Dies waren Kölner Altstadt-Pfarrkirchen, in deren Nähe die Goldschmiede saßen ${ }^{126}$. Allerdings 14 Tage vor und nach dem Weihnachtsfest wurde diese Beschränkung aufgehoben: Während des konjunkturellen Aufschwungs an Weihnachten durfte ein Goldschmied solange „wirken, aslange as he wilt"127.

Für die Begrenzung der Arbeit in der Nacht spielten gelegentlich sogar sozialpolitische Ziele eine Rolle. Ganz besonders bemerkenswert ist es schon, wenn 1444 die tägliche Arbeitszeit der Kölner Riemenschneider von 5 Uhr morgens bis 9 Uhr abends mit folgender Begründung eingeschärft und ohne Ausnahmemöglichkeit festgesetzt worden ist: Verwandte der "kinder“, die dem Amt dienten, d.h. der Lehrlinge, hätten sich darüber beklagt, „dat die kinder durch die nacht ind ungewoenlichen moissen sitzen wirken", und dies nach einem 16-stündigen Normalarbeitstag. Überdies wäre den Nachbarn durch den Lärm „ire zitiche raste", ihre Nachtruhe, genommen worden ${ }^{128}$. Die "natürliche ruhe", diesmal des Hausgesindes, wurde 1588 in der für unseren Untersuchungszeitraum recht späten, aber bemerkenswerten Frankfurter Buchdruckerordnung als Begründung herausgestellt, die Offizine ganzjährig "nur" $z$ wischen morgens 4 Uhr und abends 9 ,uhren zum feyrabendt ${ }^{\text {“ }} \mathrm{zu}$ öffnen ${ }^{129}$.

Die freiwilligen Übereinkünfte innerhalb der Zünfte vornehmlich zur Vermeidung von Konkurrenzsituationen - das war die eine Seite. Die stärkere Kontrolle von Nachtarbeit ergab sich auf der anderen Seite aus übergeordneten Zielvorstellungen der spätmittelalterlichen urbanitas.

Da war zunächst, wie schon am Kölner Beispiel gesehen, der Schutz der Nachtruhe der Städter vor Lärm als Motiv zum Verbot der Arbeit mit künstlichem Licht. Es findet sich vornehmlich bei Metallberufen, u. a. bei den Schmieden: In Feldkirch in Vorarlberg gab es dafür eine eigene „Schmiedglocke", in Luzern hat man während des 14. Jahrhunderts jeden mit Strafe bedroht, der schmiedete von der abendlichen „complet zit (usque ad pulsum hospitii)“ bzw. bis zum Morgen-

125 Gény, Stadtrecht, II, 545, 5; 549, 4.

126 Hermann Keussen, Topographie der Stadt Köln im Mittelalter, 2 Bde. (Preisschriften der Mevissen-Stiftung 2, Bonn 1884-1894; ND 1986) I, 153-219.

127 Loesch, Zunfturkunden, I, 81 f., nr. 27; Ennen, Zeitbewußtsein, 97. 1456/63 wurden diese Verbote für die Goldschmiede und Goldschläger bestätigt, der abendliche Arbeitsschluß allerdings präzisiert. Es heißt nun: „bis id echt uiren sleit “ und „as man zo s. Laurencius ind zo s. Albain nachtklocke geluit hait": Loesch, Zunfturkunden, I, 87, nr. 28.

128 Loesch, Zunfturkunden, II, 346 f., nr. 576 A. Nach chronikalischen Berichten war auch im oberschwäbischen Textilgewerbe (St. Gallen, 1526/1539) Kinder- und Nachtarbeit zur Aufbesserung des kümmerlichen Budgets von Tagelöhnerhaushalten nicht außergewöhnlich: Johannes Kesslers Sabbata mit kleineren Schriften und Briefen (St. Gallen 1902) 242, 479, 487. 129 Bücher, Schmidt, Amts- und Zunfturkunden, I, 161. 
grauen, „das man dien pfistern lütet “130. Die Definitionen, was man unter nächtlicher Arbeit verstand, gingen dabei gelegentlich sehr weit, so verbot man beispielsweise Lübecker Messingschlägern im Jahre 1400, „vor midnacht“ mit dem Klopfen zu beginnen ${ }^{131}$. Auch andere lärmige Handwerke hatten sich zu beschränken: So gebot den Buxtehuder Kürschnern die „bedeglocke“ den Feierabend ${ }^{132}$.

Auf der anderen Seite war innerhalb der spätmittelalterlichen Städte bestimmten Tätigkeiten bzw. speziellen Gewerben der lichte Tag völlig verwehrt, diesmal nicht aus Zwecken des Lärmschutzes, sondern aus anderen immissionsbedingten. Gründen. Auch hier fanden akustische Zeichen zur Regelung und Präzisierung Anwendung. In Konstanz zum Beispiel ließ der Rat das vor allem Färber, Fischverkäufer und Metzger angehende unkontrollierte Ausleeren von Kübeln undefinierbaren Inhalts auf die Gassen während des Tages verbieten. Dabei wurde noch zu Beginn des 16. Jahrhunderts bei der Kodifizierung dieser Ordnung ganz selbstverständlich das Tagesende mit dem während des Spätmittelalters in ganz Europa verbreiteten Glockenzeichen des Ave-Maria-Läutens ${ }^{133}$ definiert: Wer vor dieser „zit“ jemandem bei solch einer Entsorgungsaktion etwas überschüttete, „das syg wor mit es well“", der hatte unnachsichtig eine Strafe von 10 Schilling Pfennig zu gewärtigen. Die Buße verminderte sich übrigens, wenn der Vorübereilende verfehlt wurde - gewiß kein typischer Fall spätmittelalterlicher Stadthygiene ${ }^{134}$ ! In Luzern war es im 14. Jahrhundert verboten, während des Lichttages, „von fruo das man ze dien phistern lütet untz ze nacht, das man ze füre lütet, escher oder lou" in den See einzuführen. Überdies sollte keiner der Stadtbürger bei Tag die Abwassergräben „rumen“135. Der Colmarer Rat beschloß 1362, daß niemand abends „vor dem glókelin“ bzw. morgens „nach der torglogken deheinen kubel noch unflot in keinen bach schutten sol"136. Diese Colmarer und Luzerner Vorschriften, die in ähnlicher Weise auch die Augsburger und Berner Stadtrechte des 14. und 15. Jahrhunderts kannten ${ }^{137}$, werden im allgemeinen durch die Nürnber-

130 Für Feldkirch: Kühnel, Alltag, 12. Für Luzern: Weber, Ratsbüchlein, 12, nr. 35. Zahlreiche Beispiele für Niederdeutschland bei: Wulf, Arbeit, $74 \mathrm{f}$.

131 Webrmann, Zunftrollen, 331.

132 Margarete Schindler (Bearb.), Die älteren Buxtehuder Amtsstatuten, in: Niederdeutsches Jahrbuch 75 (1952) 8-47, bes. 27. Zu den lauten Arbeitsgängen der Kürschner: Mechthild Wiswe, Art. Kürschner, in: Reinhold Reith (Hrsg.), Lexikon des alten Handwerks. Vom Spätmittelalter bis ins 20. Jahrhundert (München 1990) 134-139.

133 Thomas Esser, Das Ave-Maria-Läuten und der „Engel des Herrn“ in ihrer geschichtlichen Entwicklung, in: Historisches Jahrbuch 23 (1907) 22-51, 247-268, 775-825, bes. 37-51, 247254.

134 Otto Feger (Bearb.), Die Statutensammlung des Stadtschreibers Jörg Vögeli (Konstanzer Stadtrechtsquellen 4, Konstanz 1951) 91, nr. 96.

135 Weber, Ratsbüchlein, 21, nr. 115; 22, nr. 119.

136 Paul Willem Finsterwalder (Bearb.), Colmarer Stadtrechte (Oberrheinische Stadtrechte III, 3, Heidelberg 1938) 296 (1386 wiederholt).

137 Christian Meyer (Bearb.), Das Stadtbuch von Augsburg, insbesondere das Stadtrecht vom Jahre 1276 (Augsburg 1872) $71 \mathrm{f}$.; Friedrich Emil Welti (Bearb.), Die Rechtsquellen des Kantons Bern, Tl. I: Stadtrechte, Bd. 2: Das Stadtrecht von Bern (Sammlung Schweizerischer 
ger Alltagspraxis bestätigt. In Nürnberg, wo die als „Pappenheimer“ bezeichneten Grubenleerer nicht wie andernorts zu den unehrlichen Berufen rechneten, sondern zu dem geschworenen Handwerk der Stadt gehörten, finden sich im Baumeisterbuch Endres Tuchers sowie in den privaten Haushaltsbüchern Anton Tuchers und Michel Behaims zuhauf Belege dafür, daß die heimlichen Gemächer durchwegs nur bei Nacht nach der Abendglocke von jenen "nachtmaistern“ geräumt worden sind ${ }^{138}$.

Das stärkste Motiv für die Normierung durch Uhr und Glocke bzw. für das Verbot nächtlichen Gewerbefleißes war sicherlich die ausgeprägte und berechtigte Furcht vor dem Ausbruch von Bränden ${ }^{139}$. Die feuergefährlichen Branchen, natürlich die Schmiede, an der Küste die Schiffbauer, die Heimarbeiter beim Flachshecheln, die Kornsieder, schließlich vor allem die Weber, wurden in ganz besonderer Weise in ihrer Arbeitsgestaltung eingeengt ${ }^{140}$. Heißt es doch bei der Begründung des Nachtarbeitverbots für die Straßburger Wollschläger: „vor ziten [wäre] grosz schade... komen" von solch nächtlichem Treiben ${ }^{141}$. Auch die Arbeitsfristen der Bäcker- und Mühlenbetriebe wurden sorgfältig reglementiert. Immerhin gingen von Bäckerhäusern und Mühlen in Basel zwischen 1475 und 1495 drei Brände aus ${ }^{142}$. In Luzern beispielsweise durften während des 15. Jahrhunderts die Stadtbäcker nur zwischen 1 Uhr nachts und $1 \mathrm{Uhr}$ nachmittags backen. Ausnahmen von dieser strengen Ordnung galten nur für diejenigen, die über feuersichere

Rechtsquellen, II, 2, Aarau 1939) 108f., nr. 235 (1435: in den Stadtbach darf niemand, „eb die glogg nach mittem tag drui slacht“, irgendwelche Unsauberkeiten schütten).

138 Lexer, Weech, Tuchers Baumeisterbuch, 113-115, 319; Carl Ludwig Sachs, Das Nürnberger Bauamt am Ausgang des Mittelalters (Neujahrblätter der Gesellschaft für fränkische Geschichte 10, München, Leipzig 1915) 59; Wilhelm Loose (Bearb.), Anton Tuchers Haushaltsbuch (1507-1517) (Bibliothek des Literarischen Vereins in Stuttgart 134, Tübingen 1877) 60 f., $98 \mathrm{f}$., 153; Johann Kamann (Bearb.), Aus Nürnberger Haushalts- und Rechnungsbüchern des 15. und 16. Jahrhunderts, in: Mitteilungen des Vereins für Geschichte der Stadt Nürnberg 7 (1886) 57-122, bes. 72 u. 102 (sehr illustrative Beispiele!). Dazu Ulf Dirlmeier, Die kommunalpolitischen Zuständigkeiten und Leistungen süddeutscher Städte im Spätmittelalter (vor allem auf dem Gebiet der Ver- und Entsorgung), in: Jürgen Sydow (Hrsg.), Städtische Versorgung und Entsorgung im Wandel der Geschichte (Stadt in der Geschichte 8, Sigmaringen 1981) 113-150, bes. 141f.; ders., Historische Umweltforschung aus der Sicht der mittelalterlichen Geschichte, in: Siedlungsforschung. Archäologie-Geschichte-Geographie 6 (1988) 97-111, bes. 106.

139 Zur Brandgefahr und ihrer Bekämpfung: Fouquet, stette buw, 456-491 mit Quellen und Literatur.

140 Vgl. dazu mit zahlreichen Beispielen: Wulf, Arbeit, 72-74; Achatz von Müller, Der Feudalismus. Land und Stadt in Mitteleuropa, in: Helmuth Schneider (Hrsg.), Geschichte der Arbeit. Vom Alten Ägypten bis zur Gegenwart (Frankfurt a.M., Berlin, Wien 1983) 155-192, bes. 181. Zum Verbot des Flachshechelns im Luzern des 14. Jahrhunderts: Weber, Ratsbüchlein, 22, nr. 122. Den Kornsiedern (Bierherstellung) in Leutkirch war 1390 die Feuerungszeit aus feuerpolizeilichen Gründen vom frühen Morgen (Mette) bis zur Vesper eingeengt worden: Ludwig Klaiber, Beiträge zur Wirtschaftspolitik oberschwäbischer Reichsstädte im ausgehenden Mittelalter (Isny, Leutkirch, Memmingen und Ravensburg), in: Vierteljahrschrift für Sozial- und Wirtschaftsgeschichte 10 (Stuttgart 1927) 117.

141 Schmoller, Tucher- und Weberzunft, 30, nr. 23.

142 Fonquet, stette buw, 476. 
Öfen verfügten ${ }^{143}$. Die Mühlen im elsässischen Schlettstadt mußten 1363 zu dem Zeitpunkt, „so furobet gelutet wurd“, stillstehen ${ }^{144}$.

Zum zweiten Aspekt: die Begrenzung und akustische Regelung der Sonn- und Feiertagsarbeit. Die Forschung der letzten Jahrzehnte konnte bei Bauhandwerkern und Tagelöhnern anhand von Abrechnungen aus dem 13. bis 15. Jahrhundert einerseits eine maximale jährliche Beschäftigungsdauer von lediglich 265 Tagen bzw. die durchschnittliche Fünf-Tage-Woche nachweisen ${ }^{145}$. Dies hat Pierre d'Ailly schon 1416 auf dem Konstanzer Konzil zu der Feststellung geführt: zuviele Festtage - die Begründung in der von Jean Gerson überlieferten Formulierung "quia dies operabiles vix sufficiunt pauperibus ad vitae necessaria procuranda “ ${ }^{146}$. Andererseits waren im Spätmittelalter Klagen über die Verstöße gegen die kirchlichen Feiertagsgebote weit verbreitet. Die Bemerkung des Erzbischofs Simon von Canterbury 1332 auf der Synode von Maghfield ist typisch dafür: Gerade an den Feiertagen fänden Tausch und Handel statt, die Wirtshäuser und Märkte seien besser besucht als die Kirchen ${ }^{147}$. Und Enea Silvio Piccolomini

143 Anne-Marie Dubler, Handwerk, Gewerbe und Zunft in Stadt und Landschaft Luzern (Luzerner Historische Veröffentlichungen 14, Luzern, Stuttgart 1982) 146. Zu weiteren Arbeitszeitbegrenzungen im oberdeutschen Bäckerhandwerk: Frank Göttmann, Die Frankfurter Bäckerzunft im späten Mittelalter. Aufbau und Aufgaben städtischer Handwerkergenossenschaften (Studien zur Frankfurter Geschichte 10, Frankfurt a.M. 1975) 57; Bernd Roeck, Bäcker, Brot und Getreide in Augsburg. Zur Geschichte des Bäckerhandwerks und zur Versorgungspolitik der Reichsstadt im Zeitalter des Dreißigjährigen Krieges (Abhandlungen zur Geschichte der Stadt Augsburg 31, Sigmaringen 1987) 223 (Augsburger Bäckerordnung 1606: vor $10 \mathrm{Uhr}$ in der Nacht sollten die Öfen nicht angebrannt und bis $10 \mathrm{Uhr}$,umb Mittag außgebacken " haben).

144 Gény, Stadtrecht, II, 785, 1; Mayer, Lebensmittel-Politik, 70.

145 Dazu sind vor allem die Arbeiten von Ulf Dirlmeier heranzuziehen: Dirlmeier, Einkommensverhältnisse, 129-133; Ulf Dirlmeier, Zu Arbeitsbedingungen und Löhnen von Bauhandwerkern im Spätmittelalter, in: Elkar, Deutsches Handwerk, 35-54, bes. 38 f. An Spezialarbeiten aus der mittlerweile zahlreich gewordenen Literatur: Willem Jappe Alberts (Bearb.), Bronnen tot de bouwgeschiedenis van de Dom te Utrecht, Bd. 2, 2: Rekeningen 1480/ 81-1506/07 (Rijks Geschiedkundige Publicatiën, Gr. Srie 129, s'-Gravenhage 1969) 785-841; Gerbard Jaritz, Die Rechnungen des Kremser "Stadtbaumeisters“ Wilbold Harber aus den Jahren 1457-1459, in: Mitteilungen des Kremser Stadtarchivs 15/16 (1976) 1-63, bes. $8 \mathrm{f}$.; Schock-Werner, Straßburger Münster, 28f.; Wolfgang Herborn, Fast-, Fest- und Feiertage im Köln des 16. Jahrhunderts, in: Rheinisches Jahrbuch für Volkskunde 25 (1983/84) 27-61; Gerhard Fouquet, „Ad structuram civitatis“: Der öffentliche Baubetrieb Hamburgs und die Errichtung von Mühlen- und Schleusenanlagen in Fuhlsbüttel während der Jahre 1465/87, in: Ulf Dirlmeier, Rainer S. Elkar, Gerbard Fouquet (Hrsg.), Öffentliches Bauen in Mittelalter und früher Neuzeit. Abrechnungen als Quellen für die Finanz-, Wirtschafts- und Sozialgeschichte des Bauwesens (Sachüberlieferung und Geschichte 9, St. Katharinen 1991) 206-292, bes. 230. Im europaweiten Vergleich: Thomas Riis, An Analysis of Working Hours, in: Diogenes 149 (1990) 65-83, bes. $72-83$.

146 Petri de Alliaco, cardinalis Cameracensis, tractatus de reformatione, seu canones reformandae ecclesiae, in: Louis Ellies Du Pin (Bearb.), Johannes Gerson. Opera omnia, Bd. 2 (Antwerpen 1706; ND 1987) 903-916, bes. 911.

147 Engelhard Eisentraut, Die Feier der Sonn- und Festtage seit dem letzten Jahrhundert des Mittelalters (Phil. Diss. Würzburg, Amorbach 1914) 17. Weiterführend zur Sonntagsheiligung und -entheiligung in der Frühen Neuzeit besonders: Andreas Heinz, Die sonn- und fei- 
schreibt um die Mitte des 15. Jahrhunderts in seiner zweiten Fassung der Beschreibung Wiens, an den Festtagen verkaufe man dort häufig Fleisch und Fisch, die Fuhrleute feierten überhaupt an keinem einzigen Tag ${ }^{148}$.

Gerade wenn man noch an die pauschalen Verbote von "knechtlicher" Arbeit an Festtagen denkt - beispielsweise erließ 1434 der Basler Bischof Johannes von Fleckenstein eine solche Ordnung ${ }^{149}$-, scheinen Handwerker und Händler nicht gerade erpicht auf festtägliche Freizeit und Muße gewesen zu sein, manche aus dem Streben nach zusätzlichen Gewinnen, viele konnten sich das Wirtshaussitzen überhaupt nicht erlauben - entweder aus Armut oder aus den branchenspezifischen Gesetzen des Marktes ${ }^{150}$. So ließ sich der bekannte Buchdrucker Christoph Froschauer aus Zürich bei einem Verhör 1522 folgendermaßen vor dem Rat der Stadt vernehmen: Er müsse „Tag und nacht, Fyrtag und Werktag“ arbeiten, „domit ich es fergen mög uff die Frankfurtermeß, und das ist nemlich die Epistel des heiligen Pauly". Feiertagsarbeit wurde also in der Offizin des Christoph Froschauer für absolut nötig gehalten, um das Buchsortiment für das lukrative Frankfurter Messegeschäft überhaupt herstellen zu können ${ }^{151}$.

Die zahlreichen Trink-, Spiel- und Tanzverbote an Sonn- und Feiertagen wie zum Beispiel in Nürnberg und Straßburg haben die tatsächlich schwierige handwerkliche Existenz völlig verstellt ${ }^{152}$. Ulf Dirlmeier bemerkt dazu mit Recht: „Bei der Entscheidung zwischen weniger Arbeit oder mehr Erwerbsmöglichkeiten scheint das Bedürfnis nach einem höheren Einkommen überwogen zu haben. "153 Die teilweise drastische Verminderung der Feiertage während der Reformation war trotz mancher damit verbundener Ausbeutungstendenzen sicherlich auch ein Werk fürsorglicher Sozialpolitik. Im reformierten Nürnberg beispielsweise wurden von 48 zusätzlichen Festtagen 28 beseitigt, wodurch die Zahl der jährlichen Arbeitstage von rund 260 auf 294 anstieg. Auch auf Hamburger Baustellen war

ertägliche Pfarrmesse im Landkapitel Bitburg-Kyllburg der alten Erzdiözese Trier von der Mitte des 18. bis zur Mitte des 19. Jahrhunderts (Trierer Theologische Studien 34, Trier 1978) 69-73.

148 Edition bei: Voigt, Berichte, 246-252, bes. 251.

149 Eisentraut, Feier, $40 \mathrm{f}$. Darüber hinaus Wulf, Arbeit, $120 \mathrm{f}$.

150 Bräuer, Arbeitszeit, 90 f.; Dirlmeier, Einkommensverhältnisse, 40 f.; Frank Göttmann, Handwerk und Bündnispolitik. Die Handwerkerbünde am Mittelrhein vom 14. bis zum 17. Jahrhundert (Frankfurter Historische Abhandlungen 15, Wiesbaden 1977) 115.

151 Salomon Vögelin, Christoph Froschauer, erster berühmter Buchdrucker in Zürich, nach seinem Leben und Wirken, nebst Aufsätzen und Briefen von ihm und an ihn: Zur 4. Säkularfeier der Erfindung der Buchdruckerkunst, den 24. Juni 1840 (Zürich 1840) 1-24, bes. 13, nr. 1; Johannes Fried (Hrsg.), Die Frankfurter Messe. Besucher und Bewunderer. Literarische Zeugnisse aus ihren ersten acht Jahrhunderten. Mit einem Essay von Hartmut Boockmann (Frankfurt a.M. 1990) 61, nr. 31. Dazu ders., Kunst und Kommerz. Über das Zusammenwirken von Wissenschaft und Wirtschaft im Mittelalter vornehmlich am Beispiel der Kaufleute und Handelsmessen (Schriften des Historischen Kollegs, Vorträge 32, München 1993) bes. $34 \mathrm{f}$.

152 Baader, Polizeiordnungen, 255 (15. Jahrhundert: Spiel- und Trinkverbot); Brucker, Polizei-Verordnungen, 207f. (1466: Verbot des Tanzens der Straßburger Fischer am Pfingstmorgen).

${ }_{153}$ Dirlmeier, Arbeitsbedingungen, $40 \mathrm{f}$. 
man nach dem Wechsel des religiösen Bekenntnisses an ca. 291 Tagen im Jahr tätig $^{154}$. Und in der Tat ist die Zahl der Verbote von Sonn- und Feiertagsarbeit bei einzelnen Handwerksbranchen während des späten 14. und 15. Jahrhunderts Legion. Ich nenne hier nur die Straßburger Armbrustergesellen - man bot ihnen dafür Nachtarbeit an -, die Kölner Leinenfärber, Lohgerber, Waffensticker, Schildermaler, Glaswörter und Bildschneider ${ }^{155}$. Die Barbiere Kölns, die bis 1442 ihre Läden an Feiertagen offenhalten konnten, mußten nun stillsitzen, das „sonnendachsscheren“ wurde „afgedan“, es wäre denn, es käme jemand aus dem „gevenknis“, von einer Pilgerfahrt oder es befänden sich König und Fürsten in der Stadt. Nur in diesen Fällen durfte man noch im sonntäglichen Köln Haare schneiden und Bärte stutzen ${ }^{156}$.

In Florenz dagegen wurde den Barbieren 1355 und 1415 wie übrigens auch den Hufschmieden und merkwürdigerweise den Schustern sogar geboten, an Sonnund Feiertagen ihr Gewerbe auszuüben ${ }^{157}$. Auch die Florentiner Ärzte durften an kirchlichen Festtagen Kranke kurieren, die Apotheker ihre Geschäfte offenhalten (1415): „mane usque ad tertiam“ und abends „post vesperas“158. Den Schneidern Nürnbergs war es am Beginn des 14. Jahrhunderts an Feiertagen nur dann gestattet, ihren Kunden Gewänder anzuprobieren, wenn die Kleider am Abend zuvor „ze kumpletzeit... dahaim“ fertiggestellt worden waren ${ }^{159}$. Und Johannes Butzbach berichtet davon, daß er in Aschaffenburg als Schneiderlehrling gerade an den großen Festen bis zur Hochmesse arbeiten mußte ${ }^{160}$.

Gänzlich dagegen ruhte wiederum jegliche festtägliche Geschäftigkeit bei den Fischern in Frankfurt/M., Straßburg und Zürich ${ }^{161}$. Die Straßburger Fischer hatten nur die Chance, am Samstag "vor der vesper" hinaus auf Ill und Rhein zu fahren. Erreichte die Kähne aber das Vesperläuten noch innerhalb genau beschriebener Grenzpunkte, dann mußten sie umkehren. Die Fischer konnten erst wieder

$154 \mathrm{Zu}$ Nürnberg: Ulf Dirlmeier, Zu den Bedingungen der Lohnarbeit im spätmittelalterlichen Deutschland, in: Annalisa Guarducci (Hrsg.), Forme ed evoluzione del lavoro in Europa: XIII-XVIII secc. (Istituto internazionale di storia economica „F. Datini“ Prato, serie II, 13, Florenz 1991) 521-558, bes. 526; Rainer Gömmel, Vorindustrielle Bauwirtschaft in der Reichsstadt Nürnberg und ihrem Umland (16.-18. Jahrhundert) (Beiträge zur Wirtschaftsund Sozialgeschichte 30, Stuttgart 1985) 207. Zu Hamburg: Wulf, Arbeit, 152-154. Zu der selbst noch nach den Reduzierungen während der Frühen Neuzeit auch in katholischen Gebieten als drückend empfundenen übergroßen Zahl von Feiertagen sowie zu den Möglichkeiten von Feiertagsarbeit: Heinz, Pfarrmesse, 73-78.

155 Brucker, Polizei-Verordnungen, 17 (1465); Loesch, Zunfturkunden, I, 45, nr. 20 (Leinenfärber); 134, nr. 49 (Lohgerber); 139, nr. 52 (Schildermaler, Glaswörter und Bildschneider); 201, nr. 77 (Waffensticker).

156 Loesch, Zunfturkunden, II, 37, nr. 215; 38, nr. 216.

157 Alfred Doren, Studien zur Florentiner Wirtschaftsgeschichte, Bd. 2: Das Florentiner Zunftwesen (Stuttgart, Berlin 1908; ND 1969) 662.

158 Doren, Studien, II, 663.

159 Schultheiß, Satzungsbücher, I, 162.

160 Andreas Beriger (Bearb.), Johannes Butzbach. Odeporicon. Eine Autobiographie aus dem Jahre 1506 (Zweisprachige Ausgabe, Weinheim 1991) $260 \mathrm{f}$.

161 Bücher, Schmidt, Amts- und Zunfturkunden, I, 202; Werner Schnyder (Bearb.), Quellen zur Zürcher Zunftgeschichte, Bd. 1: 13. Jahrhundert bis 1604 (Zürich 1936) 211, nr. 278. 
am Montagmorgen beim Blasen des Taghorns bzw. beim Läuten der Morgenglokken, wenn "men den tag hürnet" oder „das primeglöckel anzühet", die Ankerplätze verlassen, um zu ihren Fischgründen und Reusen zu gelangen ${ }^{162}$. Die Schlettstadter Müller durften an Weihnachten, Ostern und Pfingsten erst am Mittag des zweiten Feiertags ihre Arbeit aufnehmen. Bei niedrigem Wasserstand allerdings, wenn nur ein Mühlengang lief, war es den Getreidemühlen gestattet, an allen Sonntagen mit Ausnahme der Hochfeste zu mahlen. Die Versorgung der Stadt mit Mehl mußte gewährleistet sein ${ }^{163}$.

Arbeitszeitbegrenzungen gab es jedoch nicht nur an den Sonntagen und an den kirchlichen Festen, sondern, wie bei der Betrachtung der Fangfristen der Straßburger Fischer schon angeklungen, bereits an den Abenden zuvor. So liberal wie der Rat Miltenbergs, der 1379 seinen Fischern anheimstellte, „uff welche zit oder stunde sie [an Sonnabenden oder Vigilien] uß sollen faren", könnten sie selbst festlegen, war man selten ${ }^{164}$. Im spätmittelalterlichen Köln mußten zahlreiche Handwerke an den gebotenen Abenden mit dem zur Neige gehenden Lichttag, "bi schoinne dage“, ihre Arbeit einstellen, die Tätigkeit bei Kunstlicht wurde verboten ${ }^{165}$. In Nürnberg und Zürich durften zu Beginn des 14. Jahrhunderts Schneider und Tuchscherer an gebannten Abenden nicht länger bei ihrer Näharbeit sitzen, "dann als goetlich und reht ist“ (Nürnberg), vor allem sollten sie nicht „bi liecht oder morndes", bei Talglicht oder Mondschein (Zürich), bzw. nach der Feuerglocke (Nürnberg) nähen bzw. scheren ${ }^{166}$. In Villingen traf es 1490 die Schmiede und Kürschner ${ }^{167}$. Präzisere Zeitangaben sind für die Schlettstadter Müller überliefert: Hier erwartete man, daß an den Samstagen und an den Vorabenden der Marienfeiertage, „so complet gelutet und gesungen wurt zu den Barfussen“, die Mühlräder stillstanden ${ }^{168}$. Die Arbeiten beim Flachs waren in Göttingen an den Vigilien mit Ausnahme des Spinnens, zu dem man sich in die private Sphäre des Hauses zurückzog, sommers wie winters um drei Uhr einzustellen ${ }^{169}$, die vigne-

162 Brucker, Polizei-Verordnungen, 169, 172, $174 \mathrm{f}$.

163 Gény, Stadtrecht, II, 786, 5, 8. Zur Leistung der Mühlenbetriebe für eine Großstadt des 16. Jahrhunderts: Horst Kranz, Die Kölner Rheinmühlen, 2 Bde. (Aachener Studien zur älteren Energiegeschichte 1-2, Aachen 1991-1993) II, 219-227.

164 Richard Schröder, Karl Köhne (Bearb.), Miltenberg, Obernburg, Hirschhorn, Neckarsteinach, Weinheim, Sinsheim und Hilsbach (Oberrheinische Stadtrechte I, 4, Heidelberg 1898) 312 .

165 Loesch, Zunfturkunden, I, 4, nr. 1 u. II, 4, nr. 166 (1398/1483, Altschuhmacher); I, 12, nr. 4 (1397, Beutelmacher); 36 f., nr. 16 (1397, Drechsler); 110, nr. 38 (1378, Filzhutmacher); 153, nr. 55 (1397, Sattelmacher); 161, nr. 60 (1397, Schuhmacher, Kindsschuhmacher und Holzschuhmacher).

166 Zu Nürnberg: Baader, Polizeiordnungen, 135; Schultheiß, Satzungsbücher, I, 162 (1315/ 30-ca. 1360). Zu Zürich: Schnyder, Quellen, I, 33, nr. 7 (1336). In der Ordnung der Meister des Zürcher Tuchschererhandwerks von 1515/23 wieder aufgenommen: ebd. I, 170, nr. 205. 167 Hier wurde das Arbeitsverbot an den Vorabenden noch auf den Morgen der Festtage ausgedehnt: Roder, Villingen, 100, nr. 35.

168 Gény, Stadtrecht, II, 786, 5 f.

169 Goswin Freiherr von der Ropp (Bearb.), Göttinger Statuten. Akten zur Geschichte der Verwaltung und des Gildewesens der Stadt Göttingen bis zum Ausgang des Mittelalters 
rons von Metz mußten nach einem Erlaß von 1355 an den Samstagen und den Festvigilien zur Nonzeit die Weingärten verlassen ${ }^{170}$, die Schmiede in Köln hatten an den nämlichen Tagen im Winterhalbjahr um 5 Uhr, in den Sommermonaten um 7 Uhr ihre lauten Hämmer schweigen zu lassen ${ }^{171}$. Dagegen durften die Schneider der Rheinstadt nähen „van einre middernacht zo der anderre“, d.h. nicht über 12 Uhr nachts hinaus, gewiß um die zahlreichen Wünsche ihrer Kunden gerade vor Festtagen befriedigen zu können ${ }^{172}$.

Zum dritten und letzten Aspekt dieses Abschnitts: den nächtlichen Sperrstundenregelungen. Sie sind, in Massen seit dem Beginn des 14. Jahrhunderts bezeugt, in erster Linie Ausfluß des notwendig extremen, auch in anderen Lebensbereichen zu beobachtenden Sicherheitsdenkens in der „Festung“ Stadt, die im Spätmittelalter von einer wenig befriedeten Umwelt umgeben war. Gewiß gab es dabei auch schon im 14. Jahrhundert Versuche, moralische Vorstellungen über das nächtlichöffentliche Treiben der Stadtbewohner in normierende Zeitordnungen umzusetzen $^{173}$. Seit dem endenden 15. Jahrhundert gestalteten sich die Sperrstundenregelungen dann mehr und mehr zu einem Tummelfeld obrigkeitlicher Kontrolle, wie die Verbote beispielsweise des Nürnberger Rats zeigen, „nach der fewrglocken“ Hunde auf den Gassen laufen zu lassen oder von der Feuerglocke an „biß auff zwo stund vor mitternacht" ohne künstliche Beleuchtung mit den Schlitten zu fahren ${ }^{174}$. Im Jahre 1478 hat man in der fränkischen Metropole sogar eine eigene Ratsordnung für das Betteln während der Nacht erlassen: Bettlern und Bettlerinnen, die sich schämten, bei Tag ihrem bitteren Gewerbe nachzugehen, sollte es gestattet sein, beim Einbruch der Nacht nach einem „sunder[n] zeichen" noch mehrere Stunden zu betteln ${ }^{175}$.

Zur Bezeichnung der Nachtruhe wie für das Ende des gewerblichen Ausschanks von Bier und Wein kannten alle europäischen Städte bestimmte Si-

(Quellen und Darstellungen zur Geschichte Niedersachsens 25, Hannover, Leipzig 1907) 483 , nr. 279.

170 François, Tabouillot, Histoire de Metz, IV, 159.

171 Loesch, Zunfturkunden, I, 155, nr. 56. Darüber hinaus wurde den Garnmacherinnen schon 1370/97 bzw. den Nadelmachern 1397 geboten, an den Vorabenden von Festtagen winters um 5 bzw. um 4 Uhr, sommers um 6 Uhr die Arbeit zu beenden: ebd. I, 143, nr. 53; II, 154, 377.

172 Loesch, Zunfturkunden, I, $155 \mathrm{f}$., nr 57.

173 Zum Beispiel: Nürnberger Spielverbote nach der Feuerglocke (13./14. Jahrhundert): Baader, Polizeiordnungen, 63-65; Verbot in Schaffhausen, nachts "mit hornen“ zu blasen: Karl Schib (Bearb.), Die Rechtsquellen des Kantons Schaffhausen, Teil I, Bd. 2: Das Stadtrecht von Schaffhausen II: Das Stadtbuch von 1385 (Sammlung Schweizerischer Rechtsquellen XII, Aarau 1967) 81, nr. 144. Der Kölner Rat untersagte 1406 den Zünften, nach 11 Uhr nachts in den Gaffel- oder Amtshäusern zu spielen: Stein, Akten, II, 148. Zu Straßburger Spielverboten: Ernst Bender, Weinhandel und Wirtsgewerbe im mittelalterlichen Straßburg (Straßburg 1914) $99,129 \mathrm{f}$.

174 Baader, Polizeiordnungen, $94 \mathrm{f} ., 331$.

175 Im Sommer zwei, im Winter drei Stunden: Baader, Polizeiordnungen, $316 \mathrm{f}$. In Würzburg war nach der Bettlerordnung von 1490 das Betteln nachts bis zur zweiten Weinglocke erlaubt: entsprechende Personen durften "nach der andern weinglocken auff der gassen nit funden werden “: Hoffmann, Polizeisätze, 204, nr. 380. 
gnale ${ }^{176}$. In den niederländischen Kommunen beispielsweise, in Elburg, Dordrecht und Amsterdam, durfte nach der ,avondglocke“ kein Bier mehr verzapft werden, in Antwerpen hatten im 14. Jahrhundert die Tavernen zu schließen, wann die "diefclocke volluud es" ${ }^{\text {177. }}$.

Für unsere Fragestellung ist nun der Zusammenhang von allgemeiner Sperrstunde und Besuch der Wirtshäuser, der Bier- und Weinschenken, sind die akustischen Formen der Normierung der abendlichen Wirtshauszeiten von Interesse. In manchen Städten gab es dazu kein eigenes Glockensignal, man benutzte einfach die Uhrglocke. In Überlingen und Zürich beispielsweise sollten zu Beginn des 16. Jahrhunderts öffentliche Tavernen und zünftige Trinkstuben nicht länger offen gehalten werden, „dann bis die glogg nune geschlagen hatt “ ${ }^{178}$. Andere Städte beschränkten sich dagegen in der gleichen Epoche zur Bezeichnung der Sperrstunde in den Schankhäusern noch auf unverbindliche Formulierungen wie "nach der glocken des abendes" - in Eisenach, "so die abentstunde vorhanden ist " - in Gotha, "so man die nachtglocken geluden hait" - in Marburg, "so die glogk nachts leutet" - in Trier. Solche Normierungen setzten bei den Stadtbewohnern zumindest einen Verständniszusammenhang zwischen gebotener Zeit und entsprechendem Zeichen voraus ${ }^{179}$. In Marburg bezeichneten die Nachtglocken einen Zeitraum zwischen 8 und 9 Uhr. Das Ende des Ausschanks wurde dort erst 1545 auf $8 \mathrm{Uhr}$ terminiert, um, wie es schon um 1540 hieß, keinen Gast „zum volsaufen anreizung" zu geben; 1546 sollten nach dem Willen des Stadtrats die Studenten der Marburger Universität um 9 Uhr mit dem Zechen aufhören, „darmit sie zu iren studiis den morgen desda geschickter seien. Wolt aber einer studiren nach 9 urhen, das sal ime unbenommen sein. ${ }^{\text {}} 180$ Die genauen Uhrzeiten, die in den Marburger Ordnungen wie übrigens auch im kleinen Amorbach erst in der ersten Hälfte des 16. Jahrhunderts Einzug hielten ${ }^{181}$, galten zum Beispiel in Bern, Metz, Köln,

176 Vgl. z. B. Georg Steinhausen, Geschichte der deutschen Kultur, Bd. 1 (Leipzig ${ }^{4} 1936$ ) 220; Hans Conrad Peyer, Von der Gastfreundschaft zum Gasthaus. Studien zur Gastlichkeit im Mittelalter (Monumenta Germaniae historica, Schriften 31, Hannover 1987) 238.

177 B. H. D. Hermesdorf, De herberg in de Nederlanden. Een blik in de beschavingsgeschiedenis (Assen 1957) 159-161.

178 Schnyder, Quellen, I, 171, nr. 206 (1515/23: Sperrstunde in der Gesellentrinkstube des Schneiderhandwerks). Nahezu gleichlautendes Verbot in Überlingen für alle Wirtshäuser: Fritz Geier (Bearb.), Überlingen (Oberrheinische Stadtrechte II, 2, Heidelberg 1908) 251.

179 Karl Friedrich von Strenge, Ernst Devrient (Bearb.), Die Stadtrechte von Eisenach, Gotha und Waltershausen (Thüringische Geschichtsquellen 9, Jena 1909) 80, nr. 40 (1500: Eisenach); 398, Nachtrag nr. 9 (1541: Gotha); Friedrich Küch (Bearb.), Quellen zur Rechtsgeschichte der Stadt Marburg, 2 Bde. (Veröffentlichungen der Historischen Kommission für Hessen und Waldeck 13, 1-2, Marburg 1918-1931; ND 1991) I, 199 f., nr. 142; Friedrich Rudolph (Bearb.), Quellen zur Rechts- und Wirtschaftsgeschichte der rheinischen Städte. Kurtrierische Städte. I: Trier (Publikationen der Gesellschaft für Rheinische Geschichtskunde 29, Bonn 1915) 421, nr. $149(1460)$.

180 Küch, Quellen, I, 326, nr. 246; 339, nr. 258; 346, nr. 267; 361, nr. 273; 365, nr. 276.

181 Richard Schröder (Bearb.), Mergentheim, Lauda, Ballenberg und Krautheim, Amorbach, Walldürn, Buchen, Külsheim und Tauberbischofsheim (Oberrheinische Stadtrechte I, 3, Heidelberg 1897) 232 (1528: sommers 8 Uhr; winters 7 Uhr). Auch in Colmar durfte 1370 kein 
Göttingen und Hildesheim schon im späten 14. und 15. Jahrhundert zur Präzisierung des Schankschlusses ${ }^{182}$. Die Kölner Zecher blieben dabei mit ihrer recht großzügigen 11-Uhr-Regelung unerreicht im deutschsprachigen Raum des Spätmittelalters ${ }^{183}$, obgleich in der Stadt seit 1398 wesentlich restriktivere allgemeine Sperrstundenregelungen galten: von neun Uhr abends bis sieben Uhr morgens $^{184}$.

Zahlreiche Städte kannten dagegen eine ganz bestimmte Glocke zur Bezeichnung der öffentlichen Ordnung bei Nacht und zum Geschäftsende des Wirtsgewerbes: In Nürnberg, Luzern und dem oberösterreichischen Eferding beispielsweise schlug die Feuerglocke ${ }^{185}$, in Würzburg ${ }^{186}$, Speyer ${ }^{187}$, Miltenberg ${ }^{188}$, Volkach $^{189}$, in Limburg an der Lahn ${ }^{190}$ und in Trier ${ }^{191}$ hielten sich die Zecher an die Weinglocke. Im Mainzer Dom läutete die „Bretzelglocke“, in Bremen eine „Warmbierglocke“192. Bierglocken setzten in München ${ }^{193}$, merkwürdigerweise auch in Weinanbaugegenden wie in Krems und Wien den Wirten und ihren Gä-

Wirt ${ }_{n}$ nach dem gloegkelin in seinem huse ${ }^{\star}$ den Zechern noch etwas ausschenken: Finsterwalder, Stadtrechte, 292.

182 Zu Bern: Markus Escher, Das Recht des Gastgewerbes im alten Bern (Phil. Diss., Fribourg 1977) 36 (sommers $10 \mathrm{Uhr}$; winters $9 \mathrm{Uhr}$ ). Zu Metz in der sogenannten „Grand Atour" von 1405 (sommers $10 \mathrm{Uhr}$; winters $9 \mathrm{Uhr}$ ): François, Tabouillot, Histoire de Metz, IV, 564-580, bes. 574. Zum politischen Hintergrund: Jean Schneider, La ville de Metz aux XIIIe et XIVe siècles (Nancy 1950) 493-501. Im späten 15. Jahrhundert kannten die Metzer je nach Saison sogar drei verschiedene, zwischen 8 und $10 \mathrm{Uhr}$ liegende Sperrstunden. Das Nachtgeläute dauerte dabei eine halbe Stunde: Bibliothèque Nationale, Nouvelle acquisitions françaises 6697, f. $2^{\mathrm{r}}$ (freundlicher Hinweis von Alexander Reverchon, Trier). Zu Göttingen 1468 (10 Uhr) und Hildesheim 1471 (sommers 9 Uhr; winters $8 \mathrm{Uhr}$ ): Ina Tschipke, Lebensformen in der spätmittelalterlichen Stadt. Untersuchungen anhand von Quellen aus Braunschweig, Hildesheim, Göttingen, Hameln und Duderstadt (Schriftenreihe des Landschaftsverbandes Südniedersachsen 3, Hannover 1993) 31, 33, 121.

183 Für Köln zuerst 1398-1400: Stein, Akten, II, 91 f., nr. 77; 98 u. 101, nr. 80. Danach ständige Erneuerungen: ebd. II, $147 \mathrm{f}$., nr. 107 (1406: Verbot, Gäste nach 11 Uhr im Wirtshaus zu beherbergen); ebd. I, 249, nr. 92; 388, nr. 193; 681, nr. 331 (11-Uhr-Gebot: 1407-1460).

184 Die allgemeinen Sperrstunden wurden lediglich während der Zeit des Karnevals und ersten Fastenzeit (Fastabend bis Reminiscere) morgens auf 5 Uhr verkürzt. Daneben bestanden noch abweichende Regelungen: Stein, Akten, I, 206, nr. 55; 233, nr. 83; 257, nr. 94.

185 Schultbeiß, Satzungsbücher, I, 66 (1302/15); Weber, Ratsbüchlein, 12, nr. 36; 28, nr. 155; Otto Wutzel (Bearb.), Die Rechtsquellen der Stadt Eferding (Fontes rerum Austriacarum III, 2, Graz, Köln 1954) 7, nr. 7.

186 1296/97 noch als Nachtglocke, seit 1342 dann als Weinglocke bezeichnet: Hoffmann, Polizeisätze, 39, nr. 7d; 40, nr. 7j; 61 f., nr. 83; 92, nr. 217; 145, nr. 317b (bis 1474).

187 1347: Hilgard, Urkunden, 444, nr. 502; 445 f., nr. 503.

188 1379: Schröder, Köhne, Miltenberg, 316.

189 um 1500: Kramer, Alltagsleben, 32.

190 1518/37: Eiler, Stadtbuch, 101, nr. 50; 144, Anhang nr. 6 (als Sperrzeit galt hier 9 Uhr abends).

191 Rudolph, Quellen, 416, nr. 144.

192 Bader, Turm- und Glockenbüchlein, 109.

193 Pius Dirr (Bearb.), Denkmäler des Münchner Stadtrechts, Bd. 1: 1158-1403 (Bayerische Rechtsquellen 1, München 1934) 414 f., nr. 340 f.; 426, nr. 383; 511 f., nr. 16. 
sten Grenzen von Geschäft und Genuß194 . „Narrenglocke“ und „Lumpenglocke“ wiesen den Nachtschwärmern in Ulm bzw. Dillingen den Heimweg ${ }^{195}$.

In einigen Städten hat man die Glocke zur Regelung der Sperrstunde in den Wirtshäusern nur kurz angeschlagen. Andere städtische Ratskollegien berücksichtigten dagegen eher die Probleme von wein- und bierseligen Zechern: Sie lieBen die Glocken bis zu einer Stunde läuten. In Essen und Frankfurt (um 1355) hatte man dafür die sogenannte "lange Glocke" installiert ${ }^{196 . ~ D a s ~ M u ̈ n c h n e r ~}$ Stadtrechtsbuch aus der ersten Hälfte des 14. Jahrhunderts blieb im Ungefähren und stellte dazu lediglich fest: „Und wil man die glocken darumb dester spaeter und dester lenger lan láwten, daz iederman sein trinchen, daz er ân gevaerd pey der glocken im hab genommen, múg ausgetrinchen. "Die Wirte Münchens hatten diesen Vorgang allerdings mit geeigneten Maßnahmen zu beschleunigen ${ }^{197}$. Übergangsregelungen sind auch für andere Städte überliefert: in Speyer galt 1347 eine unbestimmte Frist zwischen der "wingloken und so man munster metden zu samen lutet ${ }^{\star 198}$, in Straßburg schlug den Trinkstuben und Gesellschaftshäusern 1493 präziser um Viertel vor zehn Uhr die "nůnerglock..., die man ouch ein vierteil einer stunden volliclich luten und uf die zehen ungeverlich usgelütet sin soll“". Kommunikationsproblemen suchte man dadurch vorzubeugen, daß die Hauptkannen der zünftigen Stuben Straßburgs verpflichtet waren, ihren Gästen das Schlagen der Glocke zu bedeuten („und inen sagen, das man die glock lìte“) ${ }^{199}$. Die Zürcher Wirte dagegen konnten ihre Gäste noch eine Viertelstunde länger sitzen lassen. Hier an der Limmat wurde die sogenannte "Stubglocke" auf dem St. Petersturm eine gute halbe Stunde - um 1336 umschrieb man diesen Zeitraum noch ohne Uhr mit: "als das man müssechich mochte gan ein halbe mile" - nach der Feuerglocke angezogen, welche die allgemeine Sperrstunde anzeigte. Nach einer weiteren halben Stunde erscholl dann von Fraumünster her die "Nachglocke“, das endgültige Zeichen zum Schließen der Weinhäuser ${ }^{200}$. Solch gestaffelte Regelungen hat schließlich auch Konstanz eingeführt. In der Stadt am See brauchten die Weinschenken nach einer Ordnung von 1529 niemandem, sobald „es nün am abent geschlagen hat", Wein zu geben. Es stand den Wirten allerdings frei, noch bis 10 Uhr den Weinverkauf fortzusetzen ${ }^{201}$. Selbst in den Jahren 1544/46 hat man

194 Krems (1305-1538): Otto Brunner (Bearb.), Die Rechtsquellen der Städte Krems und Stein (Fontes rerum Austriacarum III, 1, Graz, Köln 1953) 27, nr. 21 II; 134, nr. 215; 221, nr. 347. Wien kannte neben der Bierglocke auch noch das Hornblasen: Bader, Turm- und Glokkenbüchlein, $159 \mathrm{f}$.

195 Lippert, Glockenläuten, 15.

$196 \mathrm{Zu}$ Essen: Johanna Kachel, Herberge und Gastwirtschaft in Deutschland bis zum 17. Jahrhundert, in: Vierteljahrschrift für Sozial- und Wirtschaftsgeschichte 3 (Stuttgart 1924) 131. Zu Frankfurt: Wolf, Gesetze, 99, 105, $138 f$.

197 Dirr, Denkmäler, 414, nr. 340.

198 Hilgard, Urkunden, 445 f., nr. 503.

199 Brucker, Polizei-Verordnungen, 478f. (Wiederholungen noch im 15. Jahrhundert: ebd., 480f.).

200 Zeller-Werdmüller, Nabholz, Stadtbücher, I, 90f., nr. 235; 137, nr. 296; II, 326, nr. 123.

201 Feger, Statutensammlung, 40, nr. 21. 
das noch in althergebrachter Weise mit dem „dritt zaichen zu abent prediglüten“ umschrieben ${ }^{202}$. Danach mußte mit dem Trinken aufgehört werden, überdies sollte „niemands mer uff der gassen in ainicherlai wiß weder singen, juchzen, schrygen, noch ander unwesen haben “203.

Nur noch darauf hingewiesen sei, daß solche Glockenzeichen zur Regelung der Sperrstunden nahezu ausnahmslos nur für die Einheimischen, nicht für die Fremden ertönten ${ }^{204}$. Man hat auch für bestimmte Gruppen der städtischen Gesellschaft gesonderte Zeit-Ordnungen getroffen, wie beispielsweise in Straßburg und Duisburg für das unruhige Völkchen der Acker-, Dienst- und Handwerksknechte: In Straßburg durften die Gesellen im Sommer ab zehn Uhr nachts, im Winter ab 9 Uhr nicht mehr in Tavernen und "garten... zeren noch zơsammen“ kommen. Diese Einschränkungen galten ausdrücklich nicht für „herren, ritter, knechte, kouflùte, bilgerin“, da sie „erlich, redelich liot" seien ${ }^{205}$. Überdies hat man allenthalben an Sonn- und Feiertagen beschränkte Geschäftszeiten für die städtischen Bier- und Weinhäuser festgesetzt, bezeichnet durch Gottesdienstzeiten und vermittelt durch entsprechende akustische Zeichen ${ }^{206}$.

\section{Zusammenfassung}

Der Kölner Ratsherr Hermann Weinsberg (1518-†1597) erzählt am Beginn seiner bekannten Autobiographie von Schülerstreichen, davon, daß die jungen Burschen die Pfannenschläger mit der Frage nach der Uhrzeit vorzüglich zu ärgern wußten: „dan meinen sei, man beschimp sei, dweil sei doch nit wol horen. “207 Der Gang der Zeit teilte sich in den Städten des Spätmittelalters durch die akustischen Signale der Glocken mit. Man „hörte“ auf den Baustellen, in den Werkstätten, Läden und den Wirtshäusern die Zeit. Daran änderte in den deutschen Städten auch die Einführung von Uhr und Stunde seit dem sechsten Jahrzehnt des 14. Jahrhunderts nichts - im Gegenteil. Große und kleine Glocken normierten, präzisierten, rhythmisierten in Verbindung mit den öffentlichen Uhren in allen größeren Städten Oberdeutschlands Arbeits- und Geschäftszeiten, regelten das Tagewerk.

202 Feger, Statutensammlung, 196, nr. 373.

203 Feger, Statutensammlung, 130f., nr. 175.

204 Kachel, Herberge, 132.

205 Straßburger Knechteordnung von 1465: Brucker, Polizei-Verordnungen, 300. Zu Duisburg (1518): Mibm, Elmentaler, Stadtrecht, 122.

206 Allgemein: Kachel, Herberge, $133 \mathrm{f}$. Beispielsweise zu Ausschankzeiten an Feiertagen in Straßburg: Ebeberg, Straßburg, I, 142; Brucker, Polizei-Verordnungen, 542; Bender, Weinhandel, 110. In Wertheim galten sonntägliche Schankzeiten (1509/28) von 11 Uhr vormittags bis 3 Uhr nachmittags, in Limburg (1537) "nach mittag " bis 5 Uhr: Richard Schröder (Bearb.), Wertheim, Freudenberg und Neubrunn (Oberrheinische Stadtrechte I, 1, Heidelberg 1895) 43; Eiler, Stadtbuch, 144, Anhang nr. 6.

207 Höblbaum, Lau, Stein, Buch Weinsberg, I, 59. 
Die Festlegung der Signalensemble und der durch sie angezeigten Werkzeiten folgte für die zahlenmäßig große Gruppe der Lohnarbeiter während des Spätmittelalters oft und oft den Arbeitszeit- und Lohnkonflikten, die diese lediglich tageweise beschäftigten Menschen mit städtischen Räten, mit öffentlichen und privaten Arbeitgebern austrugen. Der Lichttag und seine traditionellen Glockenzeichen blieben dennoch in überwiegender Weise das Maß der Arbeit, die Uhrzeiten präzisierten hier nur die Rhythmen von Tätigkeit und Ruhe zwischen Sonnenaufgang und der hereinbrechenden Dämmerung. Die neue Stundenrechnung war keineswegs das gleichsam unveränderliche astronomische Metrum, sie entwickelte sich auch nicht dazu. Mit Hilfe verschiedener Zeitsysteme wie etwa durch die Große Uhr versuchte man vielmehr, die überkommene, sich an die kanonischen Stunden anlehnende und im Verlauf des Jahreskreises dem natürlichen Gang des Lichtes folgende Tradition der Tageseinteilung und der korrespondierenden Veränderbarkeit der Glockensignale mit der neuen Gleichförmigkeit der Äquinoktialstunden zu vereinen. Das ältere „ungefährlich“ verwob sich mit der Modernität der Stunde, der Arbeitstag und seine Pausen wurden dadurch zu rationaleren Größen vertragsrechtlicher Übereinkünfte, die Arbeitsleistung konnte nun mit Hilfe von Glocke und Uhr stärker präzisiert, freilich differenziert in den einzelnen Städten auch standardisiert werden. Dies sicherte zum einen den Arbeitsbesitzern größere Kontrollmöglichkeiten, verschaffte zum anderen den Arbeitern mehr Sicherheit vor Willkür. Es entstanden zum Ende des 15. Jahrhunderts hin neue Formen der Lohnarbeit, beispielsweise die stundenweise Beschäftigung und Entlohnung.

Bei der Begrenzung von Arbeits- und Geschäftszeiten im städtischen Handwerk verwendete man das nämliche Instrumentarium akustischer Kommunikation und stundenmäßiger Präzision. Es standen indes für jene Zeitregelungen andere Motive Pate: das Nahrungsprinzip durch Verminderung der Konkurrenz, die Ruhestörung und Feuergefahr, die von nächtlicher Lichtarbeit ausging, das Verlangen nach öffentlicher Sicherheit, das mit der Sperrstunde in Wein- und Bierhäusern verbunden war, laikale wie kirchliche Ordnungsvorstellungen setzten mit Glocken, die an den Vorabenden wie an den Sonn- und Feiertagen zu Gebet und Messe riefen, handwerklichem Tätigsein und gewerblichem Streben Schranken. Die Glocke und die ihr verbundene öffentliche Uhr entwickelten sich auch und gerade in dem seit dem späten 15. Jahrhundert zu beobachtenden Wandlungsprozeß der städtischen Ratskollegien zur alle Lebensbereiche normierenden, kontrollierenden und pädagogisierenden Obrigkeit mehr und mehr zu signifikanten Herrschaftszeichen in den Groß- und Mittelstädten des oberdeutschen und rheinischen Raumes.

Insgesamt: Die mechanischen Schlaguhren des Spätmittelalters werden in ihrer revolutionierenden Wirkung von Teilen der modernen Forschung überschätzt. Ähnlich wie für die Maß- und Gewichtssysteme ${ }^{208}$ gilt auch für die Bemessung

208 Dazu vor allem Harald Witthöft, Umrisse einer historischen Metrologie zum Nutzen der wirtschafts- und sozialgeschichtlichen Forschung: Maß und Gewicht in Stadt und Land Lü- 
der Arbeitszeit: Die Ansätze zur Rationalisierung vermehrten bloß die Vielgestaltigkeit der Messung von Zeit. „Richtig zählen und rechnen konnten mittlerweile viele, aber nicht alle liebten genaue Termine. Im Ungefähren ließ sich's gemächlicher leben, und wenn schon Absprachen, dann humane, nämlich flexible. ${ }^{209}$ Und dazu gehörten auch die kanonischen Stunden und ihre akustische Übermittlung durch die Glocken.

neburg, im Hanseraum und im Kurfürstentum/Königreich Hannover vom 13. bis zum 19.Jahrhundert, 2 Bde. (Veröffentlichungen des Max-Planck-Instituts für Geschichte 60, Göttingen 1979).

209 Borst, Computus, 73. 
